\title{
Ultrafast Excited State Relaxation of a Metalloporphyrin Revealed by Femtosecond X-ray Absorption Spectroscopy
}

\author{
Megan L. Shelby ${ }^{1,2}$, Patrick J. Lestrange ${ }^{3}$, Nicholas E. Jackson ${ }^{1,2}$, Kristoffer Haldrup ${ }^{4}$, \\ Michael W. Mara ${ }^{1,2, \dagger}$, Andrew B. Stickrath ${ }^{1, \ddagger}$, Diling Zhu ${ }^{5}$, Henrik Lemke ${ }^{5, \|}$, Matthieu \\ Chollet $^{5}$, Brian M. Hoffman ${ }^{2,{ }^{*}}$, Xiaosong Li ${ }^{3,{ }^{*}}$, and Lin X. Chen ${ }^{1,2,{ }^{*}}$ \\ ${ }^{1}$ Chemical Sciences and Engineering Division, Argonne National Laboratory, Lemont, IL 60439, \\ USA \\ 2Department of Chemistry, Northwestern University, Evanston, IL 60208, USA \\ ${ }^{3}$ Department of Chemistry, University of Washington, Seattle, WA 98195, USA \\ ${ }^{4}$ Physics Department, Technical University of Denmark, 2800 Kgs. Lyngby, Denmark \\ ${ }^{5}$ LCLS, SLAC National Laboratory, Menlo Park, California 94025, USA
}

\begin{abstract}
Photoexcited Nickel(II) tetramesitylporphyrin (NiTMP), like many open-shell metalloporphyrins, relaxes rapidly through multiple electronic states following an initial porphyrin-based excitation, some involving metal centered electronic configuration changes that could be harnessed catalytically before excited state relaxation. While a NiTMP excited state present at $100 \mathrm{ps}$ was previously identified by X-ray transient absorption (XTA) spectroscopy at a synchrotron source as a relaxed $(\mathrm{d}, \mathrm{d})$ state, the lowest energy excited state, ${ }^{1,2}$ structural dynamics before thermalization were not resolved due to the $\sim 100$ ps duration of the available X-ray probe pulse. Using the femtosecond (fs) X-ray pulses of the Linac Coherent Light Source (LCLS), the Ni center electronic configuration from the initial excited state to the relaxed $(\mathrm{d}, \mathrm{d})$ state has been obtained via ultrafast Ni K-edge XANES (X-ray Absorption Near Edge Structure) on a time scale from hundreds of femtoseconds to $100 \mathrm{ps}$. This enabled the identification of a short-lived Ni(I) species aided by time-dependent density functional theory (TDDFT) methods. Computed electronic and nuclear structure for critical excited electronic states in the relaxation pathway characterize the dependence of the complex's geometry on the electron occupation of the $3 \mathrm{~d}$ orbitals. Calculated XANES transitions for these excited states assign a short-lived transient signal to the spectroscopic signature of the $\mathrm{Ni}(\mathrm{I})$ species, resulting from intramolecular charge transfer on a timescale that has eluded previous synchrotron studies. These combined results enable us to examine the excited
\end{abstract}

\footnotetext{
"Corresponding Author; lchen@anl.gov or 1-chen@ northwestern.edu.

$\dagger$ Dept. of Chemistry, Stanford University, Stanford, CA 94305

‡Booz Allen Hamilton, 3811 North Fairfax Dr., Suite 600, Arlington, VA 22203

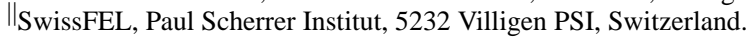

SUPPORTING INFORMATION

Characterization, data reduction, and correction of the data on a bunch-by-bunch basis; discussion of the sample excitation conditions; description of the global analysis and alternative kinetics fits; tabulated TDDFT results. This material is available free of charge via the Internet at http://pubs.acs.org.
} 
state structural dynamics of NiTMP prior to thermal relaxation and to capture intermediates of potential photocatalytic significance.

\section{Graphical abstract}

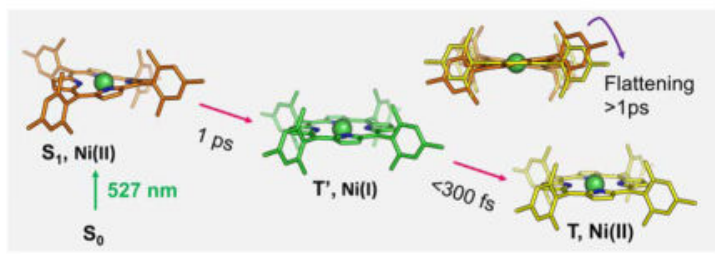

$\mathbf{S}_{0}$

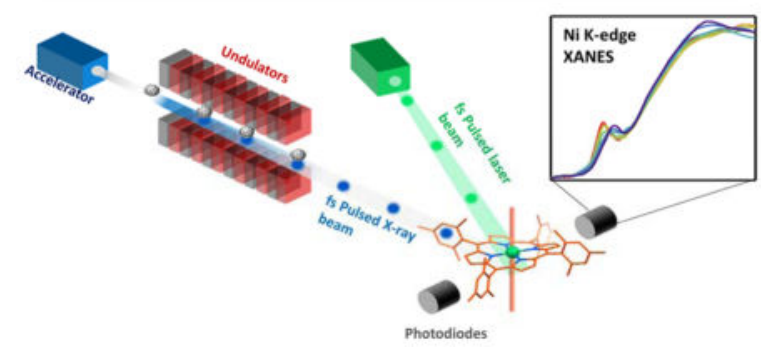

\section{INTRODUCTION}

Molecular photoexcitation generates high-energy transient species capable of driving subsequent chemical reactions. The challenge for energy conversion from light entails directing these transient species to minimize unwanted processes, such as heat generation and geminate charge recombination. Transition metal complexes (TMCs) have previously been selected for photochemical applications primarily based on the condition of possessing nanosecond or longer triplet excited state lifetimes (and large redox potentials). ${ }^{3-5}$ While such selection criteria are sufficient to ensure that a reactive species will persist, recent studies have shown that some excited TMCs can initiate photochemical processes on the picosecond or sub-picosecond timescales via singlet excited states, timescales that are competitive with vibrational relaxation, and faster than intersystem-crossing to a triplet excited state. ${ }^{1,7-12}$ Such short-lived excited states are less susceptible to energy dissipation processes that would reduce the potential driving force of a reaction. However, experimentally characterizing the TMC electronic and nuclear configurations of excited states on these timescales is challenging, making rational control difficult. Recent ultrafast optical spectroscopic measurements have provided substantial information on the reaction dynamics of TMCs, ${ }^{13-21}$ but optical signatures of metal-centered electronic transitions for these critical TMC intermediates are frequently nonexistent or obscured by $\pi \rightarrow \pi^{*}$ optical signatures localized on aromatic ligands. A greater understanding of the electronic and nuclear structural response to excitation on fs to ps timescales is needed to utilize these potentially catalytic intermediates and could be pivotal to identifying a new regime of efficient metal based photocatalysts, light sensitizers, and electron donor/acceptors that might otherwise be neglected on the basis of selection criteria focused on triplet state lifetimes. 
Pump-probe X-ray spectroscopies are element specific, and can selectively probe both the dynamic electronic structure of a TMC's metal center and its local nuclear dynamics following photoexcitation without interference from ligand-localized transitions. ${ }^{22-30}$ Recently, X-ray free electron laser (XFEL) sources capable of producing femtosecond X-ray pulses $^{31,32}$ have become available for these studies. ${ }^{22}$ We show here that combining an ultrafast X-ray source with an ultrafast optical laser pulse capable of triggering photochemical processes, allows quantitative analysis of the evolution of the electronic and nuclear dynamics of TMCs. By implementing this experimental approach along with accurate theoretical modeling, rational control over transient, catalytically-active TMC species becomes a possibility.

Metalloporphyrins possess versatile functionality as light harvesting/electron transfer cofactors, both in biological processes (natural photosynthesis, ${ }^{33,34}$ physiological oxygen transport, ${ }^{35}$ and small molecule sensing) and photocatalytic processes where they act as redox centers, ${ }^{36-38}$ and sensitizers in molecular devices. ${ }^{39}$ Such functional versatility is enabled by a high degree of chemical tunability in both the choice of metal center and the ligated macrocycle. Changes in macrocycle functionalization can dramatically impact metalloporphyrin ring conformation and rigidity, leading to varied redox and ligand binding properties, as well as the ability to impact relaxation dynamics by altering the energetic ordering of excited states. Open-shell transition metal porphyrins have not historically been seen as candidates for solar energy conversion due to their relatively fast excited state deactivation through d-orbital vacancies. While originally thought to be a disadvantage when judged with the triplet lifetime criteria, the ability to rationally control this ultrafast deactivation mechanism presents an exciting possibility for funneling the photon energy absorbed via porphyrin-based $\pi \rightarrow \pi^{*}$ transitions to redox equivalents at the metal centers via intramolecular charge transfer.

Nickel porphyrins and phthalocyanines have been of particular interest as model complexes to provide guidance for targeted molecular design in part due to their conformational flexibility brought on by the small $\mathrm{Ni}$ core size and the ease with which certain ring conformers can be stabilized to tune relaxation kinetics. Nickel (II) tetramesitylporphyrin (NiTMP), which exists in the ground state as an ensemble of ring conformers, and its analogs, have complicated photochemical dynamics and have been extensively studied by optical absorption ${ }^{6,40}$ and Raman spectroscopy. ${ }^{41-46}$ These studies, combined with quantum-mechanical calculations, proposed a plausible pathway for the photoexcitation. Within $20 \mathrm{ps}$ of the photoexcitation that initiates the $S_{0} \rightarrow S_{1}$ transition, a porphyrin macrocycle based $\pi \rightarrow \pi^{*}$ transition, the electron promoted to the $\pi^{*}$ orbital moves to an empty $3 d_{x 2-y 2}$ orbital, the highest energy ligand field state for a square-planar complex, and an electron from an originally filled $3 \mathrm{~d}_{\mathrm{z} 2}$ orbital moves to fill the hole in the $\pi$ orbital of the macrocycle left by the initial photoexcitation, resulting ultimately in the lowest-lying triplet state, $\left(3 d_{z 2}, 3 d_{x 2-y 2}\right)$. This state has a $3 d$ electronic configuration of $\left(3 d_{x 2-y 2}\right)^{1}\left(3 d_{z 2}\right)^{1}$ and is here denoted $\mathrm{T}(\mathrm{d}, \mathrm{d})$ (Figure 1). ${ }^{41,47}$ A pump-pump-probe transient absorption measurement of $\mathrm{Ni}(\mathrm{II})$ porphyrin excited state dynamics suggested that a transient $\mathrm{Ni}$ (I) charge transfer state may exist with a lifetime of a few picoseconds, ${ }^{40}$ but previously such a reaction pathway could not be substantiated by monitoring the temporal evolution of the nickel electronic configuration. In comparison to these previous optical and vibrational 
spectroscopic studies, X-ray transient absorption (XTA) spectroscopy, ${ }^{22,23}$ which combines a laser excitation and conventional X-ray absorption spectroscopy, ${ }^{48}$ can directly probe the metal center electronic structure and local geometry rather than relying on the indirect deduction of excited state dynamics from relatively broad transient optical spectral features.

Previous XTA studies at a synchrotron source (the Advanced Photon Source, Argonne National Laboratory) with $\sim 100 \mathrm{ps}$ time resolution ${ }^{1,2}$ have conclusively verified that the thermalized excited $\mathrm{T}(\mathrm{d}, \mathrm{d})$ state has an $\left(3 \mathrm{~d}_{\mathrm{x} 2-\mathrm{y} 2}\right)^{1}\left(3 \mathrm{~d}_{\mathrm{z} 2}\right)^{1}$ electronic configuration, and have captured this state's elongated $\mathrm{Ni}-\mathrm{N}$ bond length and flattened macrocycle conformation through analysis of the Extended X-ray Absorption Fine Structure (EXAFS), which arises from scattering processes with atoms neighboring the absorbing Ni. ${ }^{1,2,49}$ However, the time resolution of the synchrotron $\mathrm{X}$-ray pulses was insufficient to detect detailed excited state structural dynamics before the development of the relaxed $\mathrm{T}(\mathrm{d}, \mathrm{d})$ state. In this study, this missing time window in the evolution of excited $\mathrm{Ni}(\mathrm{II}) \mathrm{TMP}$ is obtained by collection of XTA spectra near the nickel K-edge $(8333 \mathrm{eV})$ with the sub-picosecond time resolution provided by the Linac Coherent Light Source (LCLS), an X-ray free electron capable of delivering femtosecond X-ray pulses of incredible intensity. ${ }^{28,50}$ This study has in fact disclosed a transient charge transfer state, denoted $\mathbf{T}^{\prime}$ for consistency with previous work, ${ }^{51}$ that occurs prior to the appearance of $\mathrm{T}(\mathrm{d}, \mathrm{d})$ (Figure 1) and, importantly, the X-ray absorption near edge spectra (XANES) of electronic states and geometries in the proposed photochemical trajectory were calculated and the effects of different orbital occupancies, Ni$\mathrm{N}$ bond lengths, and the magnitude of repulsive potential acting on the $\mathrm{Ni} 1 \mathrm{~s}$ electrons were correlated with trends in the experimental spectra.

\section{METHODS}

\section{Ultrafast XANES spectroscopy}

Ultrafast XANES spectra were collected for an $8 \mathrm{mM}$ solution of NiTMP in toluene at the X-ray Pump-Probe (XPP) instrument of the LCLS ${ }^{52}$ using a similar experimental configuration as previous XANES measurements at XPP. ${ }^{28}$ The sample solution was delivered to the point of spatial X-ray/laser overlap within a nitrogen filled chamber as a flat $100 \mu \mathrm{m}$ liquid jet angled at $45^{\circ}$ with respect to the incoming beam, where a pulsed laser beam nearly collinear with the incoming X-ray beam intersect. Each laser pulse generates an excited population probed by an X-ray pulse at a specified delay time with a "pump-probe" cycle of $120 \mathrm{~Hz}$. A $527 \mathrm{~nm}$ excitation pulse from the output of an optical parametric amplifier (OPA) pumped by a Ti:Sapphire laser with a pulse duration of $50 \mathrm{fs}$ (FWHM) was used to excite NiTMP through the porphyrin macrocycle centered $\mathrm{S}_{0} \rightarrow \mathrm{S}_{1}\left(\pi \rightarrow \pi^{*}\right)$ transition. The laser pulse energy at the sample was between 15 and $18 \mu \mathrm{J}$ with a spot size of $\sim 0.3 \mathrm{~mm}$ diameter. At this pulse energy, simultaneous two-photon absorption (TPA) is not expected to contribute meaningfully to the excited XAS signal due to the low TPA cross section noted for symmetrically substituted porphyrins at this energy ( 10 GM). Under these excitation conditions, the TPA excitation rate is less than $1 \%$ of the linear absorption transition rate (See Supporting Information 2 for a more detailed discussion). The absorption of the S1 state at the Q-band is very weak for similar porphyrins and sequential two photon absorption is similarly discounted. 
Ni K-edge ( $8.333 \mathrm{keV})$ XANES spectra were collected at specific pump-probe time delays by scanning a $\mathrm{Si}(111)$ double crystal $\mathrm{X}$-ray monochromator, which at this energy has a resolution of $1.2 \mathrm{eV}$, across the XFEL spontaneously amplified stimulated emission (SASE) bandwidth. The $\sim 50 \mathrm{fs}$ pulse duration X-ray probe pulses have significant bunch-to-bunch spectral and temporal fluctuations due to the variation in electron bunch characteristics, resulting in a time-integrated energy bandwidth of $\sim 50 \mathrm{eV}$ at the Ni K-edge. The peak intensity position of this distribution was tuned to the X-ray photon energy at the center of the Ni K-edge to optimize X-ray flux in the energy region of interest. The monochromatic $\mathrm{X}$-ray beam was focused to a $\sim 0.1 \mathrm{~mm}$ diameter spot at the sample with a series of Beryllium lenses. To obtain the kinetics at a specific energy, scans of the pump-probe delay were performed at fixed photon energies. For both scan types, the XANES signal for each individual X-ray pulse was collected at the $120 \mathrm{~Hz}$ repetition rate of the X-ray pulse and integrated for two seconds for a total of 240 single pulses per point.

XANES spectra were collected via $\mathrm{Ni} \mathrm{K}_{\mathrm{a}} \mathrm{X}$-ray fluorescence using two solid state passivated implanted planar silicon (PIPS) point detectors (Canberra, Inc.) at $90^{\circ}$ with respect to the incoming X-ray beam. To minimize the contribution of background counts for each fluorescence detector, the majority of the elastic scattering photons were blocked by a cobalt oxide filter mounted on a Soller slit designed for a fixed distance between the detector and the sample liquid jet $(6 \mathrm{~mm})$ and placed in front of each detector diode. The incoming monochromatic X-ray pulse intensity was monitored for later pulse-by-pulse signal normalization by another PIPS detector located upstream of the sample chamber. XANES spectra were obtained for pump-probe delay times from $-5 \mathrm{ps}$ (where the X-ray pulse precedes the laser pulse) to $100 \mathrm{ps}$ to obtain spectra for both a fully ground state population and for a comparable $\mathrm{T}(\mathrm{d}, \mathrm{d})$-ground state population mixture measured in previous experiments limited temporally by the 100 ps pulse of APS. ${ }^{1,2}$ XANES scans were smoothed with the locally weighted regression method using the number of local data points about each energy equal to $5 \%$ of the total number of points to fit the regression. Due to variation of energy step size through the scan, the energy window used in smoothing is therefore $0.6 \mathrm{eV}, 1.8 \mathrm{eV}$, and $6.6 \mathrm{eV}$ respectively for the pre edge, $4 \mathrm{p}_{\mathrm{z}}$, and white line regions of the scan, comparable or less than the $1.2 \mathrm{eV}$ energy resolution of the $\mathrm{Si}(111)$ monochromater where sharp features are interpreted.

UV-Vis absorption spectra of the sample taken before and after the XTA experiment were identical, verifying the integrity of the sample throughout data collection and discounting any contribution of irreversible damaging processes (e.g. interactions with solvated electrons, demetalation of the porphyrin, etc.) to the transient signal.

\section{Characterization of XFEL pulses and the XAS signal}

The stochastic nature of the XFEL pulse energy distribution and temporal jitter require additional characterization of both the incoming $\mathrm{X}$-ray pulse and the $\mathrm{X}$-ray fluorescence signal at the sample. For each scan step, 240 individual shots were collected and characterized according to initial intensity $\left(\mathrm{I}_{0}\right)$ and fluorescence detector response $\left(\mathrm{D}_{1}\right.$ and $\mathrm{D}_{2}$ ). The XAS signal amplitude at each energy step was determined from the average of normalized shots after rejection of selected individual shots when the normalized XAS 
signal deviated significantly from the median XAS value as described in the Supporting Information. To account for timing jitter in the X-ray pulses, individual shots were re-binned in time for time delay scans according to up-stream diagnostic RF cavities ("phase cavities") that record the average electron bunch arrival time (see Supporting Information 1 for details). Importantly, this serves to account for the long-term drift in the average pulse arrival time relative to the laser delay and replaces and reduces the contribution of the timing jitter to the overall time resolution with the uncertainty in the phase cavity response. After phase cavity rebinning, the time resolution of the experiment was reduced from an estimated $400 \mathrm{fs}$ to $300 \mathrm{fs}$ based on the FWHM of the Gaussian instrument response function obtained as a fitted variable in the fits of the time delay scans (see Methods 3 and Supporting Information 3).

\section{Global analysis of excited state kinetics}

To obtain kinetics for the NiTMP XANES evolution, pump-probe delay scans at selected characteristic X-ray photon energies were performed, primarily at those energies showing the largest signal amplitudes in the difference XANES spectra (Figure 2C). These kinetic traces were fit globally to simulated traces assuming a sequential kinetic scheme to describe the excited state decay, $\mathrm{S}_{1} \rightarrow \mathrm{T}^{\prime} \rightarrow \mathrm{T} \rightarrow \mathrm{S}_{0}$. Based on this scheme, the relative populations of each species as a function of the delay time were simulated by numerical integration of a system of differential equations. These are the differential rate expressions for each species included in the kinetic scheme. $\tau_{1}, \tau_{2}$, and $\tau_{3}$ are assigned to the first second and third steps in the sequential scheme, respectively (see Supporting Information 3). These components were weighted by their relative absorption at each energy and the total simulated kinetic traces were fit to the experimental traces using a nonlinear least squares method to obtain time constants for each step. The total absorption signals are expressed as functions of the X-ray photon energy $E$ and the pump-probe delay time $t$,

$$
A_{\text {total }}(E, t)=\sum_{i=0}^{3} A_{i}(E) P_{i}(t)
$$

Where $i$ is the index of the states, $i=0-3$, corresponding to $\mathrm{S}_{0}, \mathrm{~S}_{1}\left(\pi, \pi^{*}\right), \mathrm{T}^{\prime}$, and $\mathrm{T}(\mathrm{d}, \mathrm{d})$ states, $\mathrm{A}_{i}(\mathrm{E})$ is the relative absorption of the $i$-th state at $\mathrm{E}$, and $\mathrm{P}_{I}(t)$ is the population of $i$-th state at $t$. The relative absorption of the ground state $\mathrm{S}_{0}, \mathrm{~A}_{0}(\mathrm{E})$ and that of the $\mathrm{T}(\mathrm{d}, \mathrm{d})$ state, $\mathrm{A}_{3}(\mathrm{E})$ were respectively obtained from XANES spectra before the laser pump pulse and at $20 \mathrm{ps}$ time delay where a mixture of only the $\mathrm{T}(\mathrm{d}, \mathrm{d})$ and $\mathrm{S}_{0}$ states are present. The relative absorption of the $S_{1}\left(\pi, \pi^{*}\right)$ state $A_{1}(E)$ is assumed to be identical to $A_{0}(E)$ because the ( $\pi$, $\left.\pi^{*}\right)$ excitation is confined on the macrocycle porphine and has little impact on the nickel center. The relative absorption of the $T^{\prime}$ state $A_{2}(E)$ was treated as a variable during the fits. The calculated $\mathrm{A}_{\text {total }}$ was then convoluted with a Gaussian instrument response function (IRF), the width of which is also treated as a variable. 


\section{XANES scans in the $1 \mathrm{~s} \rightarrow 3 \mathrm{~d}$ transition pre-edge region}

In order to capture excitation induced changes in the Ni 3d-orbital occupation, the time evolution of the $1 \mathrm{~s} \rightarrow 3 \mathrm{~d}$ quadrupole-allowed transition features was also investigated by tuning the center of the SASE spectral bandwidth to this pre-edge region $(8349 \mathrm{eV})$ and collecting energy scans. Due to relatively low signal intensities of the pre-edge features, a modified scheme to compute the XTA signal at each energy step was implemented using the slope of a linear fit of $\mathrm{D}_{1}$ or $\mathrm{D}_{2}$ vs $\mathrm{I}_{0}$ rather than the average of the normalized signal for all individual shots. (see Supporting Information 1). Monochromator scans were taken only at selected time delays of $-5 \mathrm{ps}, 1 \mathrm{ps}, 10 \mathrm{ps}$ and $50 \mathrm{ps}$. Because XAS signals in the pre-edge region contain a significant background contribution from the rising edge that varies with the time delay as the nearby $1 \mathrm{~s} \rightarrow 4 \mathrm{p}_{\mathrm{z}}$ transition peak shifts in energy, a second order polynomial was used to fit the background contribution of the averaged scans for each time delay. This contribution was removed to extract the individual peaks.

\section{Electronic structure calculations}

To understand the overall electronic and structural evolution of the NiTMP excited states and to ascertain how changes in the electronic and nuclear structure as the molecule relaxes are reflected in the experimentally observed XTA signals, each electronic state in the proposed mechanism (Figure 1) was modeled separately. Initial DFT and TDDFT calculations using the BP86 functional were employed to probe the basic orbital structure of NiTMP and its excited states using the ADF package (ADF2013.01 ${ }^{53,54}$ ). A double- $\zeta$ polarized (DZP) basis set was used for the description of $\mathrm{C}, \mathrm{N}$, and $\mathrm{H}$ atoms, and a triple- $\zeta$ polarized (TZP) basis set was used to describe the atomic orbitals of $\mathrm{Ni}$. This combination of functional and basis set has previously described the orbital structure of a related $\mathrm{Ni}$ compound with high accuracy. ${ }^{55}$ Subsequently, the geometries of the ground and each intermediate excited state were optimized with the BP86 functional ${ }^{56-58}$ and the 6-31G(d) basis set ${ }^{59,60}$ using a development version of the Gaussian software package. ${ }^{58}$ The X-ray absorption was calculated with energy-specific TDDFT (ES-TDDFT) ${ }^{61,62}$ using the PBE1PBE and Ahlrichs' def2-TZVP basis set ${ }^{63}$ with diffuse functions on the nickel atom. ${ }^{64-66}$ For all calculations of X-ray absorption spectra, the mesityl groups on the porphyrin have been replaced with methyl groups to reduce computational cost.

\section{RESULTS}

\section{Experimental results}

\subsection{Ni K-edge XANES describes excited state electronic and structural}

dynamics-In the Ni K-edge XANES spectra shown in Figure 2, the spectrum at a -5 ps pump-probe time delay (before the laser arrives) is identical to the previously obtained spectrum for the ground state $\mathrm{S}_{0},{ }^{1,67}$ while the spectra at the $20 \mathrm{ps}$ time delay and longer resemble the spectrum identified by the same study as the $\mathrm{T}(\mathrm{d}, \mathrm{d})$ state. ${ }^{1,2}$

Comparing the spectra at $100 \mathrm{ps}$ delay with the $\mathrm{T}(\mathrm{d}, \mathrm{d})$ spectrum and considering the $200 \mathrm{ps}$ $\mathrm{T}(\mathrm{d}, \mathrm{d})$ state decay time constant obtained previously, we estimate the initial excited state fraction to be $\sim 60 \%$ (see Supporting Information 2). XANES features for the $S_{0}$ and $T(d, d)$ states have been assigned and share attributes characteristic of a square planar $\mathrm{Ni}(\mathrm{II})$ 
coordination geometry. A distinct peak at $8339 \mathrm{eV}$ in the $\mathrm{S}_{0}$ state spectrum and at $8341 \mathrm{eV}$ in the $\mathrm{T}(\mathrm{d}, \mathrm{d})$ state spectrum (Figure 2A, labeled E2 and E3), respectively, are assigned to the strong dipole-allowed $1 \mathrm{~s} \rightarrow 4 \mathrm{p}_{\mathrm{z}}$ transition. ${ }^{68}$ Features near the "white line" absorption peak at $8351 \mathrm{eV}$ are ascribed to contributions from multiple scattering resonances and transitions from $\mathrm{Ni} 1 \mathrm{~s}$ to $\sigma^{*}$ antibonding molecular orbitals resulting from the hybridization of $\mathrm{Ni} 4 \mathrm{p}_{\mathrm{x}}$ and $4 \mathrm{p}_{\mathrm{y}}$ orbitals with porphyrin $\mathrm{N} 2 \mathrm{~s}$ orbitals. Below the rising edge in the pre-edge region from 8330 to $8336 \mathrm{eV}$ are weak quadrupole-allowed $1 \mathrm{~s} \rightarrow$ vacant $3 \mathrm{~d}$ transitions, which directly probe the $3 \mathrm{~d}$ orbital energies and electronic occupation, ${ }^{69}$ determined by the coordination geometry and electronic state of the $\mathrm{Ni}$ center. The $4 \mathrm{p}$ orbitals are vacant for $\mathrm{Ni}$ complexes, so changes in transition energies to these orbitals, as well as to all high energy bound states, are determined by perturbations to the $4 p$ energies and changes in the energy of the core orbitals due to structural or oxidation state changes.

The progression of the electronic state population $\mathrm{S}_{0} \rightarrow \mathrm{S}_{1} \rightarrow \mathrm{T}(\mathrm{d}, \mathrm{d})$ is captured by XANES spectra taken as a function of the pump-probe delay time. The peak position of the $1 \mathrm{~s} \rightarrow 4 \mathrm{p}_{\mathrm{z}}$ transition for the $\mathrm{S}_{0}$ state at $8339 \mathrm{eV}$ (Figure 2A, label E2) clearly shifts to $8341 \mathrm{eV}$, the energy for the same transition in the $\mathrm{T}(\mathrm{d}, \mathrm{d})$ state. Meanwhile in the less well-resolved white line region, the prominent peak feature shifts from $8359 \mathrm{eV}$ to $8353 \mathrm{eV}$.

While the $\sigma^{*}{ }_{x, y}$ orbitals should shift to lower energy in the excited state as the Ni-N distances expand and the hybridization between the $\mathrm{Ni} 4 \mathrm{p}_{\mathrm{x}, \mathrm{y}}$ and $\mathrm{Ni} 2 \mathrm{~s}$ orbitals is weakened, ${ }^{70}$ the $4 \mathrm{p}_{\mathrm{z}}$ transition blue shift has not yet been well explained due to the fact that coupling between the $\mathrm{Ni} 4 \mathrm{p}_{\mathrm{z}}$ orbital and porphyrin $\pi$-orbitals is minimal.

At a glance, the spectra at time delays of -5 ps to 20 ps seem to resemble mixtures of the $\mathrm{S}_{0}$ and $\mathrm{T}(\mathrm{d}, \mathrm{d})$ states, but a feature around $8337 \mathrm{eV}$ in the difference spectra (Figure 2C) is a notable exceptions. A transient feature at $8337 \mathrm{eV}$ rises rapidly to its maximum amplitude at 400 fs to $800 \mathrm{fs}$, and decays within $\sim 2$ ps (Figures $2 \mathrm{~B}$ and $2 \mathrm{C}$ ). After $\sim 2 \mathrm{ps}$, the XANES difference reflects an increasing population of $\mathrm{T}(\mathrm{d}, \mathrm{d})$ state, whose features are fully developed by $10 \mathrm{ps}$.

The ground state $1 \mathrm{~s} \rightarrow 4 \mathrm{p}_{\mathrm{z}}$ peak depletion proceeds with an approximate time constant of $\sim 1 \mathrm{ps}$, in contrast to the growth kinetics of the $\mathrm{T}(\mathrm{d}, \mathrm{d})$ state $1 \mathrm{~s} \rightarrow 4 \mathrm{p}_{\mathrm{z}}$ peak, which displays a sharp rise after $\sim 200$ fs followed by a slower rise to the maximum peak height, suggesting the presence of an additional transient state, which we denote $\mathrm{T}^{\prime}$ (Figure 1) preceding the relaxed $\mathrm{T}(\mathrm{d}, \mathrm{d})$ state (Figure 2C, Figure 3A). The identity of the $\mathrm{T}^{\prime}$ state is considered in Results 2.1. Other dynamics of spectral features on the ps timescale include an apparent delay between the rise of the white line peak feature at $8353 \mathrm{eV}$, which is an indication of the Ni-N bond elongation as seen in the $\mathrm{T}(\mathrm{d}, \mathrm{d})$ state, and the rise of the $1 \mathrm{~s} \rightarrow 4 \mathrm{p}_{\mathrm{z}}$ transition peak associated with $\mathrm{T}(\mathrm{d}, \mathrm{d})$. Though this region of the XANES spectrum suffers due to the drop off of the X-ray intensity at the upper limit of the SASE bandwidth, it is nonetheless clear that there is little growth of this feature until 2 ps delay time, suggesting a postponed nuclear geometry change, most likely the expansion of the $\mathrm{Ni}-\mathrm{N}$ bond, relative to electronic configuration changes that lead to the blue shift of the $4 p_{z}$ peak. 
1.2 Excited state decay kinetics-Comparing time-delay scans at characteristic energies of $8338.5 \mathrm{eV}(\mathrm{E} 2), 8341 \mathrm{eV}(\mathrm{E} 3)$, and $8337 \mathrm{eV}$ (E1), the spectral feature of the short-lived transient (Figures 2C \& 3A) characterizes the decay kinetics of these electronic states along the proposed relaxation pathway (Figure 1).

As shown in Figure 3A, the bleach of the $\mathrm{S}_{0} 1 \mathrm{~s} \rightarrow 4 \mathrm{p}_{\mathrm{z}}$ signal at E2 appears to be slower than the initial rise of the $T(d, d)$ state $1 \mathrm{~s} \rightarrow 4 \mathrm{p}_{\mathrm{z}}$ at $\mathrm{E}$. The signal at $\mathrm{E} 1$ appears to rise almost instantaneously above that of the $\mathrm{S}_{0}$ state then falls to the lower $\mathrm{T}(\mathrm{d}, \mathrm{d})$ state absorption. This transient signal also interferes with the bleach of the $S_{0} 1 \mathrm{~s} \rightarrow 4 \mathrm{p}_{z}$ peak at E2, causing the kinetics of the ground state bleach to appear slower than the rise of the $\mathrm{T}(\mathrm{d}, \mathrm{d}) 1 \mathrm{~s} \rightarrow 4 \mathrm{p}_{\mathrm{z}}$ peak intensity at E3. The weak transient signal again suggests that a shortlived transient species $\mathrm{T}^{\prime}$ contributes to the overall XTA signal at those energies, manifested most noticeably at E1.

Averaged traces at each energy were thus globally fit to the sequential kinetics model below using Equation 1 as described in Methods 3, which incorporates the formation of $\mathrm{T}^{\prime}$ from the initial $S_{1}\left(\pi, \pi^{*}\right)$ state and its decay into the $T(d, d)$ state:

$$
S_{1}(\pi, \pi *) \stackrel{k_{1}}{\longrightarrow} T^{\prime} \stackrel{k_{2}}{\longrightarrow} T(d, d) \stackrel{k_{3}}{\longrightarrow} G S
$$

where $\mathrm{k}_{i}(i=1-3)$ is the rate constant and its inverse $1 / \mathrm{k}_{i}$ is $\tau_{i}$, the time constant for the $i$-th step of the reaction.

As shown by the fits to the delay scans in Figure 3A, the totality of the data can be welldescribed by the scheme of Equation 2 with three time constants; two short lifetimes, 1.0 $\pm 0.05 \mathrm{ps}$ and $0.08 \pm 0.22 \mathrm{ps}$, and one long lifetime, $400 \pm 130 \mathrm{ps}$. The $\sim 400 \mathrm{ps}$ lifetime cannot be determined accurately due to the limit of the experimental 100 ps delay time window, but it is associated with a decay of the total difference signal and can be assigned to $\tau_{3}$, the decay time constant of the $\mathrm{T}(\mathrm{d}, \mathrm{d})$ state to the ground state. This time constant has been determined previously in optical and X-ray transient absorption experiments to be $\sim 200$ ps. ${ }^{1,6}$ The 0.08 ps lifetime is within the temporal resolution of the experiment and hence cannot be precisely determined by the current data. Hence, we interpret it as less than the width of the instrument response function (FWHM, $0.29 \pm 0.17 \mathrm{ps}$ ). Because the absorption of $\mathrm{T}^{\prime}, \mathrm{A}_{2}(\mathrm{E})$ (Equation 1), is treated as a variable in the fitting, the assignment of the $1.0 \mathrm{ps}$ and $<0.3$ ps components to $\tau_{1}$ and $\tau_{2}$ is interchangeable kinetically, but can be distinguished by the very different absorption of $\mathrm{T}^{\prime}$ necessitated by the two alternatives. The scenario in which $\tau_{1}=1.0 \mathrm{ps}$ and $\tau_{2}<0.3 \mathrm{ps}$ corresponds to a $\mathrm{T}^{\prime}$ intermediate that absorbs much more than the ground state at $8337 \mathrm{eV}$ but has little accumulation due to its rapid $\tau_{2}$ decay to $\mathrm{T}(\mathrm{d}, \mathrm{d})$. The other possibility is that $\mathrm{T}^{\prime}$ appears with $\tau_{1}<0.3 \mathrm{ps}$ and decays with $\tau_{2}=1.0 \mathrm{ps}$. The alternatives have been distinguished based on the relative absorption of $\mathrm{T}^{\prime}$ at $8337 \mathrm{eV}$, where the transient XANES signal is most easily observed, and the former is preferred because with a slow decay relative to formation, $\mathrm{T}^{\prime}$ would accumulate significantly prior to decaying to $\mathrm{T}(\mathrm{d}, \mathrm{d})$. As the computational results below show that $\mathrm{T}^{\prime}$ should have a large absorption at $8337 \mathrm{eV}$, then this would require a much larger positive difference signal at this energy within the first few ps, contrary to observation. The contributions of each species in 
the relaxation pathway along with the sum total fitted signal are presented along with the experimental traces in Figure 3 for $\tau_{1}>\tau_{2}$ (Supporting Information 3 shows the fits for $\tau_{1}<$ $\left.\tau_{2}\right)$.

1.3 Ni 3d orbital configuration from pre-edge transitions-Pre-edge features corresponding to quadrupole-allowed transitions from $1 \mathrm{~s}$ to vacant $3 \mathrm{~d}$ orbitals in the nickel center provide insight into the electronic configuration of the $3 \mathrm{~d}$ orbitals. In synchrotron experiments, the pre-edge region of $\mathrm{S}_{0}$ contains a single peak for the $1 \mathrm{~s} \rightarrow 3 \mathrm{~d}_{\mathrm{x} 2-\mathrm{y} 2}$ transition arising from the electronic configuration of $\left(3 \mathrm{~d}_{\mathrm{z} 2}\right)^{2}\left(3 \mathrm{~d}_{\mathrm{x} 2-\mathrm{y} 2}\right)^{0}$ (Figure $\left.4 \mathrm{~B}, \mathrm{~S}_{0}\right){ }^{1}$ By $50 \mathrm{ps}$ after photoexcitation (Figure 4B, 1.), the $\mathrm{T}(\mathrm{d}, \mathrm{d})$ excited state is fully populated and its preedge exhibits two peaks arising from the $1 \mathrm{~s} \rightarrow 3 \mathrm{~d}_{\mathrm{x} 2-\mathrm{y} 2}$ and $1 \mathrm{~s} \rightarrow 3 \mathrm{~d}_{\mathrm{z} 2}$ transitions available for the $\left(3 \mathrm{~d}_{\mathrm{z} 2}\right)^{1}\left(3 \mathrm{~d}_{\mathrm{x} 2-\mathrm{y} 2}\right)^{1}$ electronic configuration (Figure $\left.4 \mathrm{~B}, \mathrm{~T}(\mathrm{~d}, \mathrm{~d})\right)$ which eventually decays to the ground state (Figure 4B, 4.). Looking at the time evolution of the d-orbital transition region (Figure 4A), at the negative delay representing 100\% ground state population, we see a single peak corresponding to the transition to the sole $3 \mathrm{~d}$ vacancy, $3 \mathrm{~d}_{\mathrm{x} 2-\mathrm{y} 2}$, consistent with previous synchrotron experiments. ${ }^{1,2}$ Following excitation, the $\mathrm{d}-$ orbital transitions are derived from a mixture of states which we interpret as evolving according to a series of processes represented in Figure 4B. At 1 ps delay time, the magnitude of this peak is diminished and slightly red shifted, while by $10 \mathrm{ps}$ the pre-edge features are significantly broadened with some intensity growing in at lower energy. At 50 ps delay time, we see features associated with the $T(d, d)$ state, where single vacancies in the $3 \mathrm{~d}_{\mathrm{x} 2-\mathrm{y} 2}$ and $3 \mathrm{~d}_{\mathrm{z} 2}$ lead to a split peak, although the splitting energy is $1 \mathrm{eV}$ less than the 2.3 $\mathrm{eV}$ observed at $100 \mathrm{ps}$ during synchrotron experiments. This splitting is not clearly discernable by $1 \mathrm{ps}$, but may influence the shape of the broadened features at $10 \mathrm{ps}$. The absence of a split peak by $1 \mathrm{ps}$ is contradictory to the full conversion of the excited population to $\mathrm{T}(\mathrm{d}, \mathrm{d})$ by $350 \mathrm{fs}$, as suggested by previous studies. ${ }^{71}$ Total population of the vibrationally hot $\mathrm{T}(\mathrm{d}, \mathrm{d})$ state is more consistent with the $10 \mathrm{ps}$ spectrum where the $1 \mathrm{~s} \rightarrow$ $3 \mathrm{~d}_{\mathrm{x} 2-\mathrm{y} 2}$ and $1 \mathrm{~s} \rightarrow 3 \mathrm{~d}_{\mathrm{z} 2}$ transitions appear to be broadened with the $1 \mathrm{~s} \rightarrow 3 \mathrm{~d}_{\mathrm{x} 2-\mathrm{y} 2}$ slightly higher in energy, possibly due to the shorter Ni-N bond length.

Directly detecting $\mathrm{T}^{\prime}$ features for these weakly absorbing transitions is complicated by the fact that $\mathrm{T}^{\prime}$ appears to be short lived, present at low accumulation, and exists simultaneously with several other electronic states. Features at $1 \mathrm{ps}$ are likely ascribable to a combination of the $\mathrm{S} 1$ state, $\mathrm{T}^{\prime}$, and broadened $\mathrm{T}(\mathrm{d}, \mathrm{d})$ features.

\section{Electronic structure and XANES calculation}

\subsection{TDDFT determination of excited state energies and geometries-DFT and} TDDFT calculations identified possible electronic states participating in the relaxation pathway. Ground and excited state geometry optimizations of these potential intermediate electronic states provided their relative energies and structural characteristics. (see Methods: Computational Modeling for details of the calculation and Tables S1 - S4 for calculated excited states for each geometry optimized).

Using the optimized ground state geometry, the $S_{1}\left(\pi, \pi^{*}\right)$ state Frank-Condon excitation energy, which has B excitation symmetry, is computed to lie at $2.31 \mathrm{eV}$ above the ground 
state. Any potential intermediate states in the singlet manifold should be rapidly populated according to Kasha's rule and TDDFT excited state geometry optimizations performed on the lowest lying singlet excited states of both A and B symmetry found the lowest A state at $1.31 \mathrm{eV}$ and the lowest B state at $1.81 \mathrm{eV}$. The lowest A singlet state, which possesses ( $\pi$, $3 \mathrm{~d}_{\mathrm{x} 2-\mathrm{y} 2}$ ) orbital character, is chosen as a point of probable intersystem crossing and triplet states computed using the geometry optimized in this lowest A state reveal a corresponding triplet state with the same orbital character that lies close in energy at $1.25 \mathrm{eV}$. This A state provides an excellent candidate for the identity of $\mathrm{T}^{\prime}$ because 1) it is the lowest energy state in the singlet manifold and 2$)$ the proximity of the singlet and triplet of $\left(\pi, 3 \mathrm{~d}_{\mathrm{x} 2-\mathrm{y} 2}\right)$ character in energy may enable rapid intersystem crossing.

For subsequent calculations, we identify $\mathrm{T}^{\prime}$ as a $(\pi, \mathrm{d})$ state with the d-orbital configuration $\left(3 d_{\mathrm{z} 2}\right)^{2}\left(3 d_{\mathrm{x} 2-\mathrm{y} 2}\right)^{1}$ as suggested by the experimental XANES pre-edges.

To determine any symmetry restrictions on intersystem crossing (ISC) between these electronic states, NiTMP was modeled without the mesityl substituents to obtain a higher symmetry group. Energies calculated for corresponding states of interest are very similar to those found in the lower symmetry geometry. Group theory considerations show that ISC from the singlet to triplet manifold is allowed, as the product of the irreducible representation of ${ }^{1}\left(\pi, 3 \mathrm{~d}_{\mathrm{x} 2-\mathrm{y} 2}\right)$ and ${ }^{3}\left(\pi, 3 \mathrm{~d}_{\mathrm{x} 2-\mathrm{y} 2}\right)$ belong to the irreducible representation of the angular momentum operator $\mathrm{R}_{\mathrm{z}}$.

Relaxed geometries for the ground, $S_{1}\left(\pi, \pi^{*}\right), T^{\prime}$, and $T(d, d)$ states show significant structural differences. Both the ground state and $S_{1}\left(\pi, \pi^{*}\right)$ state geometries have a short $(1.94 \AA)$ Ni-N distance and a significant out-of-plane ruffling distortion of the porphyrin macrocycle. This structural similarity is not surprising given the identical $\mathrm{Ni}$ electronic occupation in these two states. The $\mathrm{T}(\mathrm{d}, \mathrm{d})$ state, on the other hand, exhibits $1 \mathrm{~s} \rightarrow \pi$ an expansion of the Ni-N distances by $0.1 \AA$, very similar to the $0.08 \AA$ shift derived from 100 ps resolved EXAFS experiments, ${ }^{1,2}$ and a flattening of the macrocycle conformation. A 0.8 $\AA \mathrm{Ni}-\mathrm{N}$ expansion is apparent in the $\mathrm{T}^{\prime}$ state, suggesting that a relaxed $\mathrm{T}^{\prime}$ geometry would have much the same structure as the $\mathrm{T}(\mathrm{d}, \mathrm{d})$ state.

2.2 Modeling of inner shell XAS bound transitions-Solutions to the Self Consistent Field (SCF) equations that converge to at a higher energy than ground state solutions have long been recognized as useful approximations to excited state wave functions. ${ }^{72-74}$ These solutions allow excited states to be treated in a single determinant framework whose response can be modeled with TDDFT. In order to obtain these higherenergy SCF solutions, a set of natural transition orbitals (NTOs) ${ }^{75}$ for the state of interest was first generated at the excited state geometry. The initial guess for the SCF density of this higher-energy solution was then formed by a HOMO-LUMO swap of the dominant NTOs. A second-order optimization scheme was then used to converge to the state of interest. ${ }^{76}$ The XANES spectra of these intermediate states were then calculated with ES-TDDFT at the same level of theory as the ground state (discussed in Computational Modeling).

Due to the neglect of scalar and spin-orbit relativistic effects in this simulation, the calculated transitions are much lower in energy than the experimental results. However, it 
has been shown that these operators have little effect on relative transition energies ${ }^{77}$ and uniform shifts are routinely applied to calculated XANES spectra to better compare transition energies with experimental data. ${ }^{77-79} \mathrm{~A}$ uniform shift of $172 \mathrm{eV}$ is applied to all calculated spectra and all transitions are convoluted with Gaussian functions to match experimental lineshapes; 2.2 and $1.8 \mathrm{eV} \mathrm{FWHM}$ for the $4 \mathrm{p}_{\mathrm{z}}$ and $3 \mathrm{~d}$ transitions respectively.

The dipole allowed $1 \mathrm{~s} \rightarrow 4 \mathrm{p}$ transitions are the dominant transitions in all calculated XAS (Table 1, Figure 5A). The electronic environment around the $\mathrm{Ni}$ atom has changed minimally between the $S_{0}$ and $S_{1}\left(\pi, \pi^{*}\right)$ states, so little change is seen in the $1 \mathrm{~s} \rightarrow 4 p_{z}$ transition. However, a red and a blue shift is observed for the $\mathrm{T}^{\prime}$ and $\mathrm{T}(\mathrm{d}, \mathrm{d})$ states respectively. These trends reproduce those of the experimental data where the $T(d, d) 1 s \rightarrow$ $4 p_{z}$ transition is clearly blue shifted compared to the $S_{0}$ and a short-lived rise and fall is evident red of the $S_{0}$ peak. It's worth noting, however, that the calculated transitions are pure populations of their respective electronic states, which do not exist in the relaxation of the excited NiTMP and the experimental data reflects of a mixture of states.

For this system, the modeled $1 \mathrm{~s} \rightarrow 3 \mathrm{~d}$ transitions reflect the expected 3d-orbital occupation for the ground and $\mathrm{T}(\mathrm{d}, \mathrm{d})$ states. Modeled transitions to $3 \mathrm{~d}_{\mathrm{z} 2}$ and $3 \mathrm{~d}_{\mathrm{x} 2-\mathrm{y} 2}$ roughly coincide with the two peaks apparent in the experimental XANES at 50 ps delay (Figure 5B) and are very similar to those observed in the pre-edge region at $100 \mathrm{ps}$ during our previous

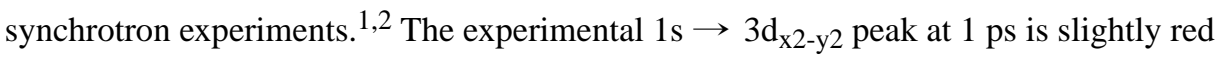
shifted compared to the ground state and this same behavior is seen for the modeled transition for the $\mathrm{T}^{\prime}$ state. This red shift is notable as it contrasts with the blue shift observed for the same transition at $50 \mathrm{ps}$ and for the modeled $\mathrm{T}(\mathrm{d}, \mathrm{d})$ state. A weakly dipole allowed $1 \mathrm{~s}$ $\rightarrow \pi$ transition is apparent in the calculated spectra of the $S_{1}\left(\pi, \pi^{*}\right)$ and $T^{\prime}$ states, although these are not plotted because their contribution is removed during background subtraction of the experimental data. Furthermore, these are relatively short-lived states, the contribution to the total signal is quite small, and this region of the spectrum is very noisy due to low XAS signal, so well-defined peaks for these weak dipole allowed transitions are not observed experimentally.

\section{DISCUSSION}

This study, which is among early examples of XTA measurements at LCLS, allows us to establish a kinetic scheme describing the decay of photo-excited NiTMP and to distinguish the short-lived $\mathrm{Ni}(\mathrm{I})$ state $\mathrm{T}^{\prime}$ as an intermediate preceding the formation of the previously characterized $\mathrm{T}(\mathrm{d}, \mathrm{d})$ state. Inner-shell transitions characterized by the combined experimental and computational results are analyzed to derive properties not directly measureable using other ultrafast methods. Here, we discuss the evidence for the charge transfer nature of the short-lived $\mathrm{T}^{\prime}$ state, discuss the interpretation of the modeled XAS transitions towards discerning the impact of electronic occupation on Ni orbital energies, reflect on the role of structure in determining excited state properties, and present our views on the implications of our findings for potential applications. 


\section{Evidence for a transient $\mathrm{Ni}(\mathrm{I})$ center due to intramolecular electron transfer}

In combination with calculated XAS transitions relating transient XANES features to corresponding electronic states, global analysis of the XTA signal as a function of the X-ray photon energy and delay time allowed us to overcome challenges in the assignment of $\mathrm{T}^{\prime}$ to a CT state: 1) the weak $\mathrm{T}^{\prime}$ state signal compared to those of the $\mathrm{S}_{0}$ and $\mathrm{T}(\mathrm{d}, \mathrm{d})$ states through the rising-edge; 2) the ambiguity of previous ultrafast optical absorption measurements with regards to changes in the Ni orbital occupation; and 3) the uncertainty of the correlation between the $3 \mathrm{~d}$ electronic configuration and the energy of the prominent $1 \mathrm{~s} \rightarrow 4 \mathrm{p}_{\mathrm{z}}$ transition.

Global fitting of kinetic traces at three characteristic X-ray energies obtained time constants for the three-step sequential model (Equation 2). However, the assignment of these time constants to specific processes requires an idea of the relative absorption properties of each state involved. This was determined with the DFT assignment of the difference XANES spectral feature at E1 to the $1 \mathrm{~s} \rightarrow 4 \mathrm{p}_{\mathrm{z}}$ transition peak of the $\mathrm{T}^{\prime}$ state. This assignment would have been otherwise challenging due to evolving background signals near the rising edge and the lack of available XANES data for $\mathrm{Ni}(\mathrm{I})$ square planar systems. The decomposition of the total signal (Figure 3b) shows that the apparently faster rise at E2 compared to the decay at $\mathrm{E} 1$ arises from a small positive contribution to the signal from $\mathrm{T}^{\prime}$ at both energies that rises and decays quickly. The kinetics of the $\mathrm{T}^{\prime}$ state absorption (Figure 3B, cyan curves) initially appear to be the result of an ultrafast ( $<300 \mathrm{fs}$ ) generation time constant $\tau_{1}$ and a relatively slow ( $1 \mathrm{ps}$ ) decay time constant $\tau_{2}$ for the $\mathrm{T}^{\prime}$ species. However, taken by itself the integrated rate law for the $\mathrm{T}^{\prime}$ population (Equation S7) derived from the sequential kinetic model (Equation 2) cannot distinguish between this assignment and $\tau_{1}=1 \mathrm{ps}$, and $\tau_{2}$ $<0.3 \mathrm{ps}$. This second case results in low $\mathrm{T}^{\prime}$ population accumulation. Given the expected large absorption of $\mathrm{T}^{\prime}$ at $8337 \mathrm{eV}$ due to its red shifted $1 \mathrm{~s} \rightarrow 4 \mathrm{p}_{\mathrm{z}}$ transition, the modest increase in signal at this energy supports the latter assignment.

Because the $\mathrm{T}^{\prime}$ state decays significantly faster than it forms, so-called "inverted kinetics" govern the $\mathrm{T}^{\prime}$ population. The $1 \mathrm{ps}$ decay of the $\mathrm{T}^{\prime}$ population reflects the $1 \mathrm{ps}$ decay of the $S_{1}\left(\pi, \pi^{*}\right)$ population from which $T^{\prime}$ is being constantly generated, while the $<0.3$ ps decay of the $\mathrm{T}^{\prime}$ state limits $\mathrm{T}^{\prime}$ accumulation even when the population of $S_{1}\left(\pi, \pi^{*}\right)$ is large. This manifests as the population rise time and the rise of the $T(d, d)$ state closely follows the rate of formation of this intermediate state, as this is essentially rate limiting. These population kinetics follow our observation that the transient $\mathrm{T}^{\prime}$ state is only detectable for 1-2 ps.

Relaxation through a charge transfer (CT) state that produces a transient Ni(I) intermediate has been previously hypothesized based on double-excitation optical methods that observed the relaxation of an excited $\pi$ electron through d-orbital vacancies in the long-lived $\mathrm{T}(\mathrm{d}, \mathrm{d})$ state in NiTPP. ${ }^{40}$ Such a CT state has also been implicated as the route of excited porphyrin deactivation in Ni tetraphenylporphyrin (NiTPP), Ni octaethylporphyrin (NiOEP), heme ${ }^{80}$, and several other open-shell metalloporphyrins ${ }^{81}$ by pump-probe photoelectron spectroscopy measurements in the gas phase, which report fast time constants for the evolution of the NiOEP excited state absorption very similar to this work (100 fs and $1.2 \mathrm{ps}$ ). 
A short lived CT state, $\mathrm{T}^{\prime}$, is compatible with the population of the $\mathrm{T}(\mathrm{d}, \mathrm{d})$ state on the picosecond time scale as observed by previous studies, ${ }^{71,82}$ although these did not implicate a charge transfer state and depicted the $S_{1}\left(\pi, \pi^{*}\right)$ relaxation process as the direct transfer of the excitation to the metal center, resulting in a hot $\mathrm{T}(\mathrm{d}, \mathrm{d})$ state. Vibrational relaxation of the hot $\mathrm{T}(\mathrm{d}, \mathrm{d})$ state was observed within 10-20ps.

During this period, vibrational relaxation processes likely occur and these results do not preclude the involvement of an unrelaxed $\mathrm{T}(\mathrm{d}, \mathrm{d})$ state in the $\mathrm{S}_{1}$ decay. However, a purely vibrational model that does not assign $\mathrm{T}^{\prime}$ as a $\mathrm{CT}$ state is not as well supported by the current analysis of the $4 p_{z}$ region, where XANES differences before $T(d, d)$ is fully populated are ascribed to the rearrangement of the $\mathrm{Ni}$ electronic structure. Ni orbital energies calculated for a $\mathrm{T}(\mathrm{d}, \mathrm{d})$ electronic configuration but an $\mathrm{S}_{0}$ or $\mathrm{S}_{1}$ geometry, approximating an unrelaxed $\mathrm{T}(\mathrm{d}, \mathrm{d})$ state, show that such a state cannot account for the transient signal at 8337 $\mathrm{eV}$ due to an overall blue shift in the $1 \mathrm{~s} \rightarrow 4 \mathrm{p}_{\mathrm{z}}$ transition (Table 1).

Nuclear movement during vibrational relaxation affects the $3 \mathrm{~d}$ orbital energies, especially those involved in coordination to the porphyrin ring, which is reflected in the dynamics of the $1 \mathrm{~s} \rightarrow 3 \mathrm{~d}$ transition region as general broadening of the $3 \mathrm{~d}$ transitions in $\mathrm{T}(\mathrm{d}, \mathrm{d})$. An increased linewidth for NiTMP $1 \mathrm{~s} \rightarrow 3 \mathrm{~d}$ transitions due to conformational heterogeneity was previously observed for the NiTMP ground state. 2 This may provide an explanation of the apparent broadening of $3 \mathrm{~d}$ transitions at $10 \mathrm{ps}$ when $\mathrm{T}(\mathrm{d}, \mathrm{d})$ is fully populated although a full description of the relaxation processes in terms of nuclear movement requires additional measurement with more direct structurally sensitive techniques.

\section{XAS transitions reflect photoinduced electronic structural changes in the metal center}

Because it directly probes transient metal orbital energies and occupancy, XTA on the fs time scale can determine the dynamics of photoinduced metal electronic configuration and orbital energy changes well before thermalization of the excited states. While optical transient absorption measurements can clearly identify the kinetics of $S_{1}\left(\pi, \pi^{*}\right)$ state decay, they are not able to directly detect optically dark electronic states arising from changes in metal centered electronic occupation or metal orbital energy changes in subsequent excited states. This study has directly obtained energies of the transitions $1 \mathrm{~s} \rightarrow 3 \mathrm{~d}$ and $1 \mathrm{~s} \rightarrow 4 \mathrm{p}_{\mathrm{z}}$ in $\mathrm{Ni}$ for different electronic states, from which these properties have been obtained for shortlived transient states.

Changes in the observed Ni K-edge transition features, such as the red shift and subsequent blue shift of the $1 \mathrm{~s} \rightarrow 4 \mathrm{p}_{\mathrm{z}}$ transition energy, agreed with the calculated inner shell transitions (Table 1) and their energies are interpreted in terms of the evolving electronic configuration. With the assignment of $\mathrm{T}^{\prime}$ to $\mathrm{Ni}(\mathrm{I}), \mathrm{T}^{\prime}$ state formation can be understood as the intramolecular charge transfer from the $\pi^{*}$ orbital to the $3 \mathrm{~d}_{\mathrm{x} 2 \mathrm{y} 2}$ orbital. Computational results indicate a rise of the $1 \mathrm{~s}$ energy by $\sim 2 \mathrm{eV}$ for the $\mathrm{T}^{\prime}$ electronic configuration, where charge transfer results in greater nuclear shielding and therefore a lower electron binding energy. The rise of the $1 \mathrm{~s}$ orbital energy in turn reduces the $1 \mathrm{~s} \rightarrow 4 \mathrm{p}_{\mathrm{z}}$ transition energy in the $\mathrm{T}^{\prime}$ state. This is identical to the core-level shift seen in X-ray photoelectron spectroscopy (XPS $)^{83}$ and the effect of oxidation on K-edge spectra has also been observed in previous XAS experiments. ${ }^{84,85}$ 
This computed red shift is seen experimentally as the rise and fall of intensity around E1 in $<2$ ps. Only about $0.2 \mathrm{eV}$ of the $\sim 2 \mathrm{eV}$ shift in the $1 \mathrm{~s} \rightarrow 4 \mathrm{p}_{\mathrm{z}}$ transition energy change from the ground state to the $T^{\prime}$ state transition is due to the shift of the $4 p_{z}$ orbital energy. Similarly, the blue shift in the $1 \mathrm{~s} \rightarrow 4 \mathrm{p}_{\mathrm{z}}$ transition energy of the $\mathrm{T}(\mathrm{d}, \mathrm{d})$ state can be attributed to a change in the repulsive potential felt by the core electrons as the $3 d_{x 2-y_{2}}$ orbital is far more hybridized with the ligand orbitals than the $3 \mathrm{~d}_{\mathrm{z} 2}$ orbital (See Figure S7). Relative to the ground state, which has a doubly occupied $3 \mathrm{~d}_{\mathrm{z} 2}$ and an unoccupied $3 \mathrm{~d}_{\mathrm{x} 2 \mathrm{y} 2}$ orbital, the $\mathrm{T}(\mathrm{d}, \mathrm{d})$ state has less electron density around the $\mathrm{Ni}$ atom, lowering the 1s orbital energy and blue-shifting the $1 \mathrm{~s} \rightarrow 4 \mathrm{p}_{\mathrm{z}}$ transition by $1.5 \mathrm{eV}$.

As evidenced by the computed changes in the Ni 1s energy experimental $1 \mathrm{~s} \rightarrow 3 \mathrm{~d}$ transition energies cannot be solely relied upon to determine changes in d-orbital splitting. Though the $1 \mathrm{~s} \rightarrow 3 \mathrm{~d}_{\mathrm{x} 2-\mathrm{y} 2}$ transitions, for example, are within half an $\mathrm{eV}$ of each other according to the experimental spectrum, we can expect the $3 d_{x 2-y 2}$ orbital energy to change much more significantly to remain consistent with the shifts in the Ni 1s energy. Calculated transition energies (see Supporting Information 4) are very similar to those experimentally observed with the possible exception of the $\mathrm{T}(\mathrm{d}, \mathrm{d})$ state, though even here the trend in the movement of the transitions with respect to the ground state is preserved.

\section{Macrocycle structural response to NiTMP electronic evolution}

The identification by TDDFT of $\mathrm{T}^{\prime}$ as the lowest energy singlet as well as a state with a triplet state lying close in energy lends credence to the identification of $T^{\prime}$ as a $(\pi, d)$ state. The optimized geometries of the involved electronic states (Figure 6) provide insight into the behavior of the NiTMP structure in response to electronic changes and the subsequent energetic rearrangement of $\mathrm{Ni}$ orbitals.

Macrocycle expansion and flattening in the $\mathrm{T}(\mathrm{d}, \mathrm{d})$ state is explained based on the net movement of electron density from $3 \mathrm{~d}_{\mathrm{z} 2}$ to $3 \mathrm{~d}_{\mathrm{x} 2-\mathrm{y} 2}$, which sits in the porphyrin plane and aligns well with the Ni-N bonds. This bond expansion is a repulsive response to additional electron density localized between the $\mathrm{Ni}$ and $\mathrm{N}$ atoms. Because the macrocycle need no longer accommodate the unusually short $\mathrm{Ni}-\mathrm{N}$ bond length, the constrained ruffled geometry relaxes to a more energetically favorable flattened conformation that allows greater delocalization of $\pi$ electrons. Interestingly, the majority of the Ni-N bond length expansion has already occurred in the relaxed geometry of the $\mathrm{T}^{\prime}$ state, which has a flattened porphyrin conformation and a Ni-N bond length expansion of $0.08 \AA$, suggesting that the occupation of $3 \mathrm{~d}_{\mathrm{x} 2-\mathrm{y} 2}$ is the main driver of porphyrin expansion.

Comparisons to $1 \mathrm{~s}, 4 \mathrm{p}_{\mathrm{z}}$, and $3 \mathrm{~d}$ orbital energies calculated for the $\mathrm{T}^{\prime}$ and $\mathrm{T}(\mathrm{d}, \mathrm{d})$ optimized geometries but using the ground state wave function to describe the electronic state are used to separate electronic vs. structural effects on the excited-state XANES. In spite of the significant difference in structure between the ground state and the $\mathrm{T}^{\prime}$ and $\mathrm{T}(\mathrm{d}, \mathrm{d})$ states, the difference in the $4 \mathrm{p}_{\mathrm{z}}$ orbital energies is very modest and the shift in the 1s energy is only about $-0.3 \mathrm{eV}$ for both geometries (Table 1 ). We can therefore conclude that the $1 \mathrm{~s} \rightarrow 4 \mathrm{p}_{\mathrm{z}}$ transition energy is largely determined by the electronic state of $\mathrm{Ni}$, which is in line with the fact that the 1s shift dominates the observed transition shifts and that $4 \mathrm{p}_{\mathrm{z}}$ has less interaction with ligand orbitals than other valence Ni orbitals. The relative insensitivity of the $1 \mathrm{~s} \rightarrow 4 \mathrm{p}_{z}$ 
energy to solely structural changes in the porphyrin conformation and $\mathrm{Ni}-\mathrm{N}$ bond length also discounts the explanation of the short-lived transient signal as pure vibrational broadening of the $\mathrm{T}(\mathrm{d}, \mathrm{d})$ state $1 \mathrm{~s} \rightarrow 4 \mathrm{p}_{\mathrm{z}}$ feature.

Based on our observation of the $\mathrm{Ni}(\mathrm{I})$ state's lifetime and the corresponding structural evolution, we can speculate on the participation of the ring structure and conformation on the stabilization of this species. Porphyrins with large out-of-plane ground state distortions generally have dramatically different photophysical properties compared to analogous planar porphyrins, exhibiting low fluorescence yield and shorter excited state lifetimes owing to an increase in accessible nonradiative decay pathways through a high degree of conformational flexibility. ${ }^{42,86}$ A TDDFT survey of Ni porphine, NiTPP and NiOEP singlet and triplet states noted that the lowest energy singlet states in all cases are CT states of ${ }^{1}\left(\pi, 3 \mathrm{~d}_{\mathrm{x} 2-\mathrm{y} 2}\right)$ character, the energy of which increases for NiTPP which has a higher degree of macrocycle out-of-plane distortion, in this case ruffling. ${ }^{55}$ Meanwhile, the lowest energy triplet state, the $\mathrm{T}(\mathrm{d}, \mathrm{d})$ state, is destabilized to an even greater degree as ruffling increases, reducing the energy gap between these states and $\left(\pi, 3 \mathrm{~d}_{\mathrm{x} 2-\mathrm{y} 2}\right)$ states. This suggests that not only are more routes to radiation-less deactivation available for distorted porphyrins, but the relevant electronic states along the proposed route of deactivation are closer together in energy and the decay process is faster according to the energy gap law.

In the ground state, Ni porphyrins have a low barrier to interconversion between various distorted conformers of the macrocycle, ${ }^{87,88}$ e.g., ruffled, domed, etc., as evidenced by the relative broadness of the $1 \mathrm{~s} \rightarrow 3 \mathrm{~d}_{\mathrm{x} 2 \mathrm{y} 2}$ transition peak. ${ }^{2}$ The lowest in energy of these conformers is a ruffled geometry according to our own geometry optimization. Geometry optimizations of the $\mathrm{T}^{\prime}$ state indicate the Ni-N bond length should expand, and therefore flatten the macrocycle. Based on the delay in the rise of the white line feature at $8353 \mathrm{eV}$, closely related to the $\mathrm{Ni}-\mathrm{N}$ bond length, with respect to the features associated with the $1 \mathrm{~s}$ $\rightarrow 4 \mathrm{p}_{\mathrm{z}}$, this expansion is delayed compared to the change in the electronic state. Because the $\mathrm{T}^{\prime}$ state appears to initially retain a ruffled geometry while the molecular structure has yet to respond to the electronic change, its conversion to the $T(\mathrm{~d}, \mathrm{~d})$ may be accelerated by the structural effect mention above, causing relaxation to $\mathrm{T}(\mathrm{d}, \mathrm{d})$ to occur before the molecule has time to flatten.

Out-of-plane distortions are structural factors that influence electronic state energies mainly through the destabilization of the $\pi$ and $3 \mathrm{~d}_{\mathrm{x} 2 \mathrm{y} 2}$ orbitals, an effect that when taken to a greater extreme in substituted Ni phthalocyanines begins to lead to longer $\mathrm{CT}$ state lifetimes. While the CT state reported here and in previous studies of Ni porphyrins is very short-lived, on the order of $<2$ ps, octamethyl and octabutoxy substituted Ni phthalocyanines have been described as having long-lived LMCT states with lifetimes in the hundreds of picoseconds. ${ }^{86,89}$ Here, ring substitution leads to the decrease of the relative CT state energy compared to the equivalent $\left(3 \mathrm{~d}_{\mathrm{x} 2-\mathrm{y} 2}, 3 \mathrm{~d}_{\mathrm{z} 2}\right)$ state to the point where the CT state is the lowest energy triplet state, extending the lifetime of the $\mathrm{Ni}(\mathrm{I})$ to the point of potential catalytic utility. 


\section{CONCLUSION}

Ultrafast XANES at the Ni K-edge was successfully measured for optically excited $\mathrm{Ni}(\mathrm{II}) \mathrm{TMP}$ on a previously unachievable sub-picosecond timescale, providing insight into its ultrafast electronic and structural relaxation processes. Importantly, a transient $\mathrm{Ni}(\mathrm{I})(\boldsymbol{\pi}, \mathrm{d})$ electronic state $\left(\mathrm{T}^{\prime}\right)$ is implicated as an intermediate through the interpretation of a shortlived excited state absorption. The assignment of this absorption is confirmed by agreement with calculated XAS transitions for the postulated $(\pi, d)$ electronic states at this energy.

The observed and computed inner shell-to-valence orbital transition energies demonstrate and quantify the influence of electronic configuration on specific metal orbital energies. The strong influence of the valence orbital occupation on the inner shell orbital energies indicates that one should not use the transition energy from $1 \mathrm{~s}$ alone to draw conclusions about the dorbital energies of different states. A transient electronic configuration could influence dorbital energies up to a few $\mathrm{eV}$ and any potential photocatalytic application should account for this to ensure that energy levels are well matched and that the photoexcitation can be used optimally in driving desirable processes.

NiTMP structural dynamics have been deduced from DFT optimized geometries and structurally sensitive features in the Ni K-edge XANES. Structural changes such as macrocycle expansion and flattening appear to have little impact on the energies of $\mathrm{Ni}$ axial orbitals observed in this study compared to the electronic changes that occur as the molecule relaxes. However, the influence of the porphyrin macrocycle conformation on relaxation kinetics may be significant enough to affect the kinetics that govern the limited population accumulation of $\mathrm{Ni}(\mathrm{I})$. The short lifetime of the $\mathrm{T}^{\prime}$ state and the delay of the nuclear rearrangement to a longer $\mathrm{Ni}-\mathrm{N}$ bond length and flattened macrocycle with respect to its formation suggests the still-ruffled macrocycle expedites $\mathrm{T}^{\prime}$ decay.

\section{Supplementary Material}

Refer to Web version on PubMed Central for supplementary material.

\section{Acknowledgments}

We acknowledge support for this work from the Solar Energy Photochemistry program (experimental work) and Ultrafast Initiative (theoretical work) of the U. S. Department of Energy, Office of Science, Office of Basic Energy Sciences, through Argonne National Laboratory under Contract No. DE-AC02-06CH11357 and MLS is supported by the National Institute of Health, under Contract No. R01-GM115761 (LXC) and R01-HL63203 (BMH). Use of the Linac Coherent Light Source (LCLS), SLAC National Accelerator Laboratory, is supported by the U.S. Department of Energy, Office of Science, Office of Basic Energy Sciences under Contract No. DEAC02-76SF00515. Computations on modeled spectra were facilitated through the use of advanced computational, storage, and networking infrastructure provided by the Hyak supercomputer system at the University of Washington, funded by the Student Technology Fee. PJL is also grateful for support by the State of Washington through the University of Washington Clean Energy Institute. MLS also thanks the National Institute of General Medical Sciences of NIH for support through the Molecular Biophysics training grant administered by Northwestern University (5T32 GM008382). KH gratefully acknowledges support from DANSCATT and from the Villum and Carlsberg Foundations. The authors would like to thank Tim Brandt Van Driel for invaluable assistance with the phase cavity timing correction by providing a means to calibrate the phase cavity data. 


\section{ABBREVIATIONS}

XTA X-Ray Transient Absorption

XANES X-ray Absorption Near Edge Structure

XAS X-ray Absorption Spectroscopy

WAXS Wide-Angle X-ray Scattering

EXAFS Extended X-ray Absorption Fine Structure

NiTMP Nickel(II) tetramesityl porphyrin

APS Advanced Photon Source

LCLS Linac Coherent Light Source

DFT density functional theory

TDDFT time dependent density functional theory

TMC transition metal complex

XFEL X-ray Free Electron Laser

SASE spontaneously amplified stimulated emission

XPP X-ray Pump Probe

CT Charge Transfer

ISC intersystem crossing

\section{References}

1. Chen LX, Zhang X, Wasinger EC, Attenkofer K, Jennings G, Muresan A, Lindsey Jonathan S. J Am Chem Soc. 2007; 129:9616. [PubMed: 17636917]

2. Chen LX, Zhang X, Wasinger EC, Lockard JV, Stickrath AB, Mara MW, Attenkofer K, Jennings G, Smolentsev G, Soldatov A. Chem Sci. 2010; 1

3. Alstrum-Acevedo JH, Brennaman MK, Meyer TJ. Inorg Chem. 2005; 44:6802. [PubMed: 16180838]

4. Ardo S, Meyer GJ. Chem Soc Rev. 2009; 38:115. [PubMed: 19088971]

5. Kalyanasundaram K, Gratzel M. Coord Chem Rev. 1998; 177:347.

6. Zhang XY, Wasinger EC, Muresan AZ, Attenkofer K, Jennings G, Lindsey JS, Chen LX. J Phys Chem A. 2007; 111:11736. [PubMed: 17966996]

7. Andersson J, Puntoriero F, Serroni S, Yartsev A, Pascher T, Polivka T, Campagna S, Sundstrom V. Chem Phys Lett. 2004; 386:336.

8. Benko G, Kallioinen J, Korppi-Tommola JEI, Yartsev AP, Sundstrom V. J Am Chem Soc. 2002; 124:489. [PubMed: 11792221]

9. Diamantis P, Gonthier JF, Tavernelli I, Rothlisberger U. J Phys Chem B. 2014; 118:3950. [PubMed: 24611869]

10. Henry W, Coates CG, Brady C, Ronayne KL, Matousek P, Towrie M, Botchway SW, Parker AW, Vos JG, Browne WR, McGarvey JJ. J Phys Chem A. 2008; 112:4537. [PubMed: 18438991] 
11. Shaw GB, Styers-Barnett DJ, Gannon EZ, Granger JC, Papanikolas JM. J Phys Chem A. 2004; 108:4998.

12. Yoon S, Kukura P, Stuart CM, Mathies RA. Mol Phys. 2006; 104:1275.

13. Cho S, Mara MW, Wang X, Lockard JV, Rachford AA, Castellano FN, Chen LX. J Phys Chem A. 2011; 115:3990. [PubMed: 21361265]

14. Hua L, Iwamura M, Takeuchi S, Tahara T. PCCP. 2015; 17:2067. [PubMed: 25479581]

15. Iwamura M, Watanabe H, Ishii K, Takeuchi S, Tahara T. J Am Chem Soc. 2011; 133:7728. [PubMed: 21524124]

16. Mance JG, Felver JJ, Dexheimer SL. J Phys Chem C. 2014; 118:11186.

17. Rury AS, Sension RJ. Chem Phys. 2013; 422:220.

18. Schrauben JN, Dillman KL, Beck WF, McCusker JK. Chem Sci. 2010; 1:405.

19. van der Veen RM, Cannizzo A, van Mourik F, Vlcek A Jr, Chergui M. J Am Chem Soc. 2011; 133:305. [PubMed: 21162574]

20. Waechtler M, Guthmuller J, Kupfer S, Maiuri M, Brida D, Popp J, Rau S, Cerullo G, Dietzek B. Chemistry-a European Journal. 2015; 21:7668.

21. Zheldakov IL, Ryazantsev MN, Tarnovsky AN. J Phys Chem Lett. 2011; 2:1540.

22. Chen LX, Zhang X, Shelby ML. Chem Sci. 2014; 5:4136.

23. Chen LX, Zhang XY. J Phys Chem Lett. 2013; 4:4000.

24. Dell'Angela M, Anniyev T, Beye M, Coffee R, Fohlisch A, Gladh J, Katayama T, Kaya S, Krupin O, LaRue J, Mogelhoj A, Nordlund D, Norskov JK, Oberg H, Ogasawara H, Ostrom H, Pettersson LGM, Schlotter WF, Sellberg JA, Sorgenfrei F, Turner JJ, Wolf M, Wurth W, Nilsson A. Science. 2013; 339:1302. [PubMed: 23493709]

25. Ferrer A, Johnson JA, Huber T, Mariager SO, Trant M, Grubel S, Zhu D, Chollet M, Robinson J, Lemke HT, Ingold G, Milne C, Staub U, Beaud P, Johnson SL. Appl Phys Lett. 2015; 106

26. Kern J, Tran R, Alonso-Mori R, Koroidov S, Echols N, Hattne J, Ibrahim M, Gul S, Laksmono H, Sierra RG, Gildea RJ, Han G, Hellmich J, Lassalle-Kaiser B, Chatterjee R, Brewster AS, Stan CA, Glockner C, Lampe A, DiFiore D, Milathianaki D, Fry AR, Seibert MM, Koglin JE, Gallo E, Uhlig J, Sokaras D, Weng TC, Zwart PH, Skinner DE, Bogan MJ, Messerschmidt M, Glatzel P, Williams GJ, Boutet S, Adams PD, Zouni A, Messinger J, Sauter NK, Bergmann U, Yano J, Yachandra VK. Nat Commun. 2014; 5

27. Kim KH, Kim JG, Nozawa S, Sato T, Oang KY, Kim T, Ki H, Jo J, Park S, Song C, Sato T, Ogawa K, Togashi T, Tono K, Yabashi M, Ishikawa T, Kim J, Ryoo R, Kim J, Ihee H, Adachi S. Nature. 2015:518. [PubMed: 25822792]

28. Lemke HT, Bressler C, Chen LX, Fritz DM, Gaffney KJ, Galler A, Gawelda W, Haldrup K, Hartsock RW, Ihee H, Kim J, Kim KH, Lee JH, Nielsen MM, Stickrath AB, Zhang WK, Zhu DL, Cammarata M. J Phys Chem A. 2013; 117:735. [PubMed: 23281652]

29. Mitzner R, Rehanek J, Kern J, Gul S, Hattne J, Taguchi T, Alonso-Mori R, Tran R, Weniger C, Schroder H, Quevedo W, Laksmono H, Sierra RG, Han GY, Lassalle-Kaiser B, Koroidov S, Kubicek K, Schreck S, Kunnus K, Brzhezinskaya M, Firsov A, Minitti MP, Turner JJ, Moeller S, Sauter NK, Bogan MJ, Nordlund D, Schlotter WF, Messinger J, Borovik A, Techert S, de Groot FMF, Fohlisch A, Erko A, Bergmann U, Yachandra VK, Wernet P, Yano J. J Phys Chem Lett. 2013; 4:3641. [PubMed: 24466387]

30. Zhang WK, Alonso-Mori R, Bergmann U, Bressler C, Chollet M, Galler A, Gawelda W, Hadt RG, Hartsock RW, Kroll T, Kjaer KS, Kubicek K, Lemke HT, Liang HYW, Meyer DA, Nielsen MM, Purser C, Robinson JS, Solomon EI, Sun Z, Sokaras D, van Driel TB, Vanko G, Weng TC, Zhu DL, Gaffney KJ. Nature. 2014; 509:345. [PubMed: 24805234]

31. Berrah N, Bozek J, Costello JT, Duesterer S, Fang L, Feldhaus J, Fukuzawa H, Hoener M, Jiang YH, Johnsson P, Kennedy ET, Meyer M, Moshammer R, Radcliffe P, Richter M, Rouzee A, Rudenko A, Sorokin AA, Tiedtke K, Ueda K, Ullrich J, Vrakking MJJ. J Mod Opt. 2010; 57:1015.

32. Emma P, Akre R, Arthur J, Bionta R, Bostedt C, Bozek J, Brachmann A, Bucksbaum P, Coffee R, Decker FJ, Ding Y, Dowell D, Edstrom S, Fisher A, Frisch J, Gilevich S, Hastings J, Hays G, Hering P, Huang Z, Iverson R, Loos H, Messerschmidt M, Miahnahri A, Moeller S, Nuhn HD, Pile G, Ratner D, Rzepiela J, Schultz D, Smith T, Stefan P, Tompkins H, Turner J, Welch J, White W, Wu J, Yocky G, Galayda J. Nat Photon. 2010; 4:641. 
33. Blankenship, RE. Molecular Mechanisms of Photosynthesis. Balckwell Science; Oxford: 2002.

34. Gust D, Moore TA, Moore AL. Acc Chem Res. 2001; 34:40. [PubMed: 11170355]

35. Frauenfelder H, McMahon BH, Fenimore PW. Proc Natl Acad Sci. 2003; 100:8615. [PubMed: 12861080]

36. Rosenthal J, Bachman J, Dempsey JL, Esswein AJ, Gray TG, Hodgkiss JM, Manke DR, Luckett TD, Pistorio BJ, Veige ASG, ND. Coord Chem Rev. 2005; 249:1316.

37. Graham DJ, Nocera DG. Organometallics. 2014; 33:4994.

38. Yang JY, Nocera DG. J Am Chem Soc. 2007; 129:8192. [PubMed: 17552520]

39. Holten D, Bocian DF, Lindsey JS. Acc Chem Res. 2002; 35:57. [PubMed: 11790089]

40. Zamyatin AV, Gusev AV, Rodgers MAJ. J Am Chem Soc. 2004; 126:15934. [PubMed: 15584706]

41. Kim D, Kirmaier C, Holten D. Chem Phys. 1983; 75:305.

42. Retsek JL, Drain CM, Kirmaier C, Nurco DJ, Medforth CJ, Smith KM, Sazanovich IV, Chirvony VS, Fajer J, Holten D. J Am Chem Soc. 2003; 125:9787. [PubMed: 12904044]

43. Gentemann S, Nelson NY, Jaquinod L, Nurco DJ, Leung SH, Medforth CJ, Smith KM, Fajer J, Holten D. J Phys Chem B. 1997; 101:1247.

44. Jia SL, Jentzen W, Shang M, Song XZ, Ma JG, Scheidt WR, Shelnutt JA. Inorg Chem. 1998; 37:4402. [PubMed: 11670577]

45. Song Y, Haddad RE, Jia SL, Hok S, Olmstead MM, Nurco DJ, Schore NE, Zhang J, Ma JG, Smith KM, Gazeau S, Pécaut J, Marchon JC, Medforth CJ, Shelnutt JA. J Am Chem Soc. 2005; 127:1179. [PubMed: 15669857]

46. Shelnutt JA, Majumder SA, Sparks LD, Hobbs JD, Medforth CJ, Senge MO, Smith KM, Miura M, Luo L, Quirke JME. J Raman Spectrosc. 1992; 23:523.

47. Jeong DH, Kim D, Cho DW, Jeoung SC. Journal of Raman Spectroscopy. 2001; 32:487.

48. van Bokhoven, J.; Lamberti, C., editors. X-ray Absorption and X-ray Emission Spectroscopy: Theory and Applications. Wiley \& Sons; New York: 2015.

49. Chen LX. J Electron Spectrosc Relat Phenom. 2001; 119:161.

50. Katayama T, Inubushi Y, Obara Y, Sato T, Togashi T, Tono K, Hatsui T, Kameshima T, Bhattacharya A, Ogi Y, Kurahashi N, Misawa K, Suzuki T, Yabashi M. Appl Phys Lett. 2013; 103

51. $\mathrm{T}^{\prime}$ and $\mathrm{T}(\mathrm{d}, \mathrm{d})$ are so named for historical reasons and for consistency with previous studies by both our group and others. Becuase $\mathrm{T}(\mathrm{d}, \mathrm{d})$ is the lowest energy triplet state, it is assumed that this relatively long lived state is a triplet. $\mathrm{T}^{\prime}$ is assigned by some studies to a hot triplet (d,d) state generated by energy transfer and intersystem crossing within instrument response. However, due to the inability of XANES to distinguish between spin states in this case, this study can not definitively assign $\mathrm{T}^{\prime}$ or $\mathrm{T}(\mathrm{d}, \mathrm{d})$ to a triplet state nor does it provide direct evidence of intersystem crossing.

52. Chollet M, Alonso-Mori R, Cammarata M, Damiani D, Defever J, Delor JT, Feng Y, Glownia JM, Langton JB, Nelson S, Ramsey K, Robert A, Sikorski M, Song S, Stefanescu D, Srinivasan V, Zhu D, Lemke HT, Fritz DM. Journal of Synchrotron Radiation. 2015; 22:503. [PubMed: 25931060]

53. Fonseca Guerra C, Snijders JG, te Velde G, Baerends EJ. Theor Chem Acc. 1998; 99:391.

54. te Velde G, Bickelhaupt FM, Baerends EJ, Fonseca Guerra C, van Gisbergen SJA, Snijders JG, Ziegler T. J Comput Chem. 2001; 22:931.

55. Patchkovskii S, Kozlowski PM, Zgierski MZ. J Chem Phys. 2004; 121:1317. [PubMed: 15260674]

56. Becke AD. J Chem Phys. 1986; 84:4524.

57. Perdew J. Phys Rev B. 1986; 33:8822.

58. Frisch, MJ.; Trucks, GW.; Schlegel, HB.; Scuseria, GE.; Robb, MA.; Cheeseman, JR.; Scalmani, G.; Barone, V.; Mennucci, B.; Petersson, GA.; Nakatsuji, H.; Caricato, M.; Li, X.; Hratchian, HP.; Izmaylov, AF.; Bloino, J.; Zheng, G.; Sonnenberg, JL.; Hada, M.; Ehara, M.; Toyota, K.; Fukuda, R.; Hasegawa, J.; Ishida, M.; Nakajima, T.; Honda, Y.; Kitao, O.; Nakai, H.; Vreven, T., Jr; JAM; Peralta, JE.; Ogliaro, F.; Bearpark, M.; Heyd, JJ.; Brothers, E.; Kudin, KN.; Staroverov, VN.; Keith, T.; Kobayashi, R.; Normand, J.; Raghavachari, K.; Rendell, A.; Burant, JC.; Iyengar, SS.; Tomasi, J.; Cossi, M.; Rega, N.; Millam, JM.; Klene, M.; Knox, JE.; Cross, JB.; Bakken, V.; Adamo, C.; Jaramillo, J.; Gomperts, R.; Stratmann, RE.; Yazyev, O.; Austin, AJ.; Cammi, R.; Pomelli, C.; Ochterski, JW.; Martin, RL.; Morokuma, K.; Zakrzewski, VG.; Voth, GA.; Salvador, 
P.; Dannenberg, JJ.; Dapprich, S.; Daniels, AD.; Farkas, O.; Foresman, JB.; Ortiz, JV.; Cioslowski, J.; Fox, DJ. Gaussian Development Version. Gaussian Inc; Wallingford, CT: 2010. Revision H.12+ ed

59. Rassolov VA, Pople JA, Ratner MA, Windus TL. J Chem Phys. 1998; 109:1223.

60. Hariharan PC, Pople JA. Theor Chem Acc. 1973; 28:213.

61. Liang W, Fischer SA, Frisch MJ, Li X. J Chem Theor Comput. 2011; 7:3540.

62. Lestrange PJ, Nguyen PD, Li X. J Chem Theor Comput. 2015; 11:2994-2999.

63. Weigend F, Ahlrichs R. Phys Chem Chem Phys. 2005; 7:3297. [PubMed: 16240044]

64. Rappoport D, Furche F. J Chem Phys. 2010; 133:134105. [PubMed: 20942521]

65. Schuchardt KL, Didier BT, Elsethagen T, Sun L, Gurumoorthi V, Chase J, Li J, Windus TL. J

Chem Inf Model. 2007; 47:1045. [PubMed: 17428029]

66. Feller D. J Comp Chem. 1996; 17:1571.

67. Chen LX, Jäger WJH, Jennings G, Gosztola DJ, Munkholm A, Hessler JP. Science. 2001; 292:262. [PubMed: 11303096]

68. Kau LS, Spira-Solomon DJ, Penner-Hahn JE, Hodgson KO, Solomon EI. J Am Chem Soc. 1987; 109:6433.

69. Westre TE, Kennepohl P, DeWitt JG, Hedman B, Hodgson KO, Solomon EI. J Am Chem Soc. 1997; 119:6297.

70. Campbell L, Tanaka S, Mukamel S. Chem Phys. 2004; 299:225.

71. Rodriguez J, Holten D. The Journal of Chemical Physics. 1989; 91:3525.

72. Gilbert ATB, Besley NA, Gill PMW. J Phys Chem A. 2008; 112:13164. [PubMed: 18729344]

73. Davidson ER. J Chem Phys. 1964; 41:656.

74. Peng B, Van Kuiken BE, Ding F, Li X. J Chem Theor Comput. 2013; 9:3933.

75. Martin RL. J Chem Phys. 2003; 118:4775.

76. Bacskay GB. Chem Phys. 1981; 61:385.

77. DeBeer George S, Petrenko T, Neese F. Inorg Chem Acta. 2008; 361:965.

78. Besley NA, Asmuruf FA. Phys Chem Chem Phys. 2010; 12:12024. [PubMed: 20714478]

79. Fronzoni G, De Francesco R, Stener M. J Phys Chem B. 2005; 109:10332. [PubMed: 16852252]

80. Ha-Thi MH, Shafizadeh N, Poisson L, Soep B. Physical Chemistry Chemical Physics. 2010; 12:14985. [PubMed: 20949219]

81. Sorgues S, Poisson L, Raffael K, Krim L, Soep B, Shafizadeh N. J Chem Phys. 2006; 124:114302. [PubMed: 16555883]

82. Mizutani Y, Uesugi Y, Kitagawa T. J Chem Phys. 1999; 111:8950.

83. Fadley CS, Hagstrom SBM, Klein MP, Shirley DA. J Chem Phys. 1968; 48:3779.

84. Sarangi R, DeBeer George S, Rudd DJ, Szilagyi RK, Ribas X, Rovira C, Almeida M, Hodgson KO, Hedman B, Solomon EI. J Am Chem Soc. 2007; 129:2316. [PubMed: 17269767]

85. Gu W, Wang H, Wang K. Dalton Trans. 2014; 43:6406. [PubMed: 24604143]

86. Drain CM, Gentemann S, Roberts JA, Nelson NY, Medforth CJ, Jia S, Simpson MC, Smith KM, Fajer J, Shelnutt JA, Holten D. J Am Chem Soc. 1998; 120:3781.

87. Alden RG, Crawford BA, Doolen R, Ondrias MR, Shelnutt JA. J Am Chem Soc. 1989; 111:2070.

88. Alden RG, Ondrias MR, Shelnutt JA. J Am Chem Soc. 1990; 112:691.

89. Balakrishnan G, Soldatova AV, Reid PJ, Spiro TG. J Am Chem Soc. 2014; 136:8746. [PubMed: 24841906] 


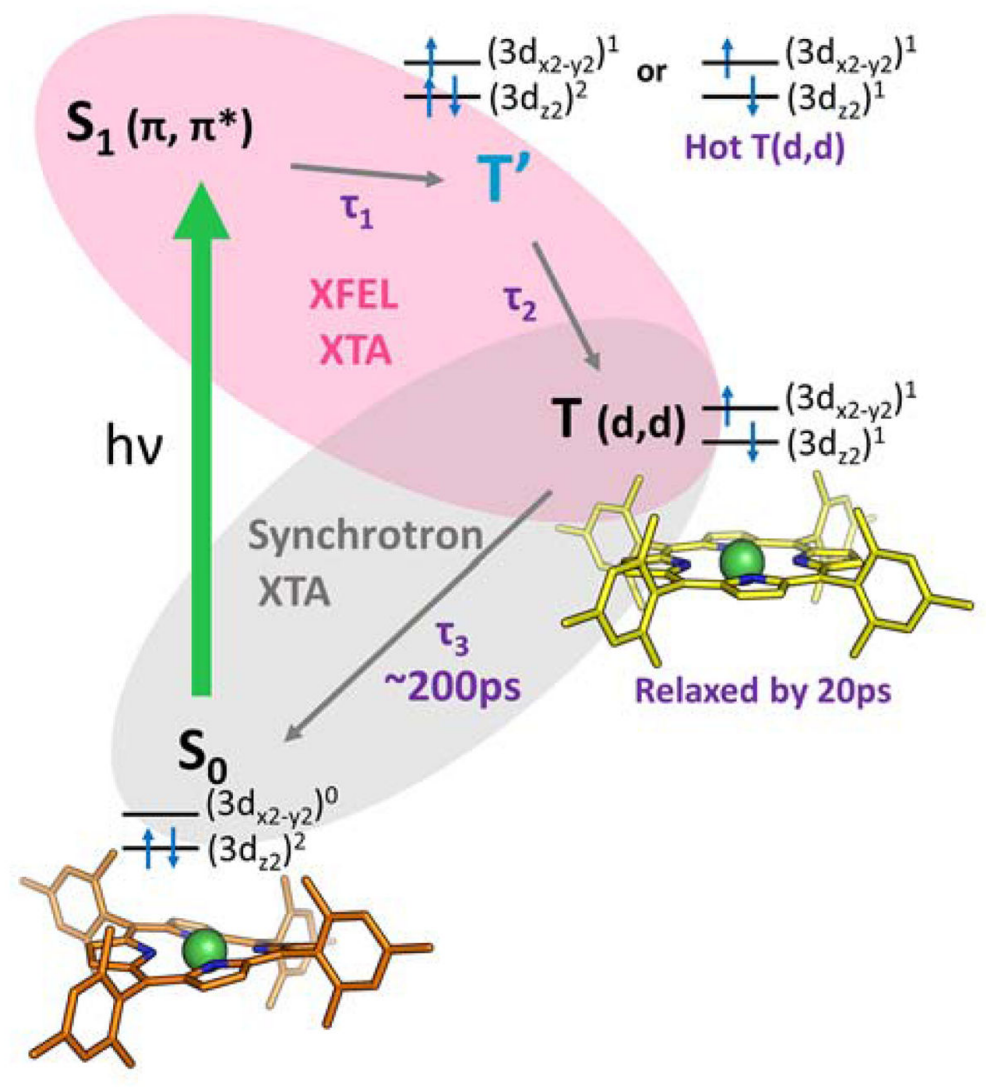

Figure 1.

The relaxation pathway of NiTMP following Q-band excitation (e.g. at $527 \mathrm{~nm}$ ). Structures for states characterized by XTA are shown. Within a few ps the porphyrin macrocycle $S_{1}(\pi$, $\left.\pi^{*}\right)$ population has dissipated by transfer of the excitation to the metal center. The resulting state $\left(\mathrm{T}^{\prime}\right)$ is therefore either a hot $\left(3 \mathrm{~d}_{\mathrm{z} 2}, 3 \mathrm{~d}_{\mathrm{x} 2-\mathrm{y} 2}\right)$ state which decays to the relaxed $\left(3 \mathrm{~d}_{\mathrm{z} 2}\right.$, $\left.3 d_{x 2-y 2}\right)$ state $\mathrm{T}(\mathrm{d}, \mathrm{d})$ via vibrational relaxation or a $\left(\pi, 3 \mathrm{~d}_{\mathrm{x} 2-\mathrm{y} 2}\right)$ state with $\mathrm{Ni}(\mathrm{I})$ character that transfers an electron back to the ligand. By 20 ps the $T(d, d)$ state is fully populated and vibrationally relaxed, and has adopted a flattened structure with elongated Ni-N bonds. ${ }^{2}$ This $T(d, d)$ state decays back to the ground state with a 200 ps lifetime. ${ }^{6}$ 

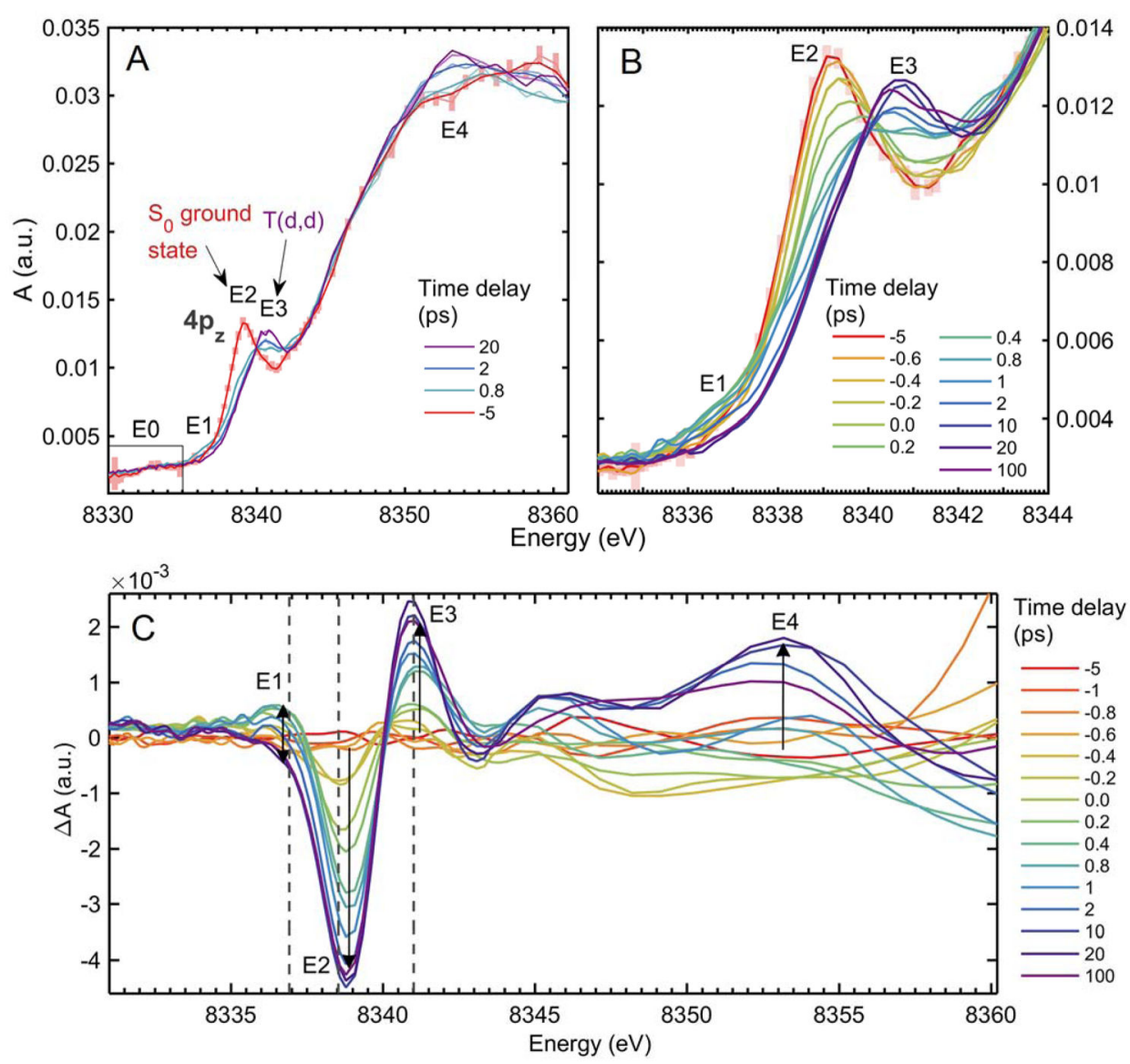

Figure 2.

Smoothed Ni K-edge XANES spectra of NiTMP between -5 and 100 ps following $527 \mathrm{~nm}$ excitation. Numbered energies correspond to: E0. The $1 \mathrm{~s} \rightarrow 3 \mathrm{~d}$ transition ("pre edge") region E1. a transient at the low-energy end of the $1 \mathrm{~s} \rightarrow 4 \mathrm{p}_{\mathrm{z}}$ region, E2. the $S_{0} 1 \mathrm{~s} \rightarrow 4 \mathrm{p}_{\mathrm{z}}$ transition, E3. the $\mathrm{T}(\mathrm{d}, \mathrm{d}) 1 \mathrm{~s} \rightarrow 4 \mathrm{p}_{\mathrm{z}}$ transition, and E4. the white-line feature associated with shortened Ni-N bonds in the T(d,d) state. (A) Time delays characteristic of ( $-5 \mathrm{ps}) \mathrm{S}_{0}$, plotted with $95 \%$ confidence intervals to show the level of the error throughout the data set, (0.4 ps) the peak of the transient signal at $8337 \mathrm{eV},(2 \mathrm{ps})$ the partial disappearance of the transient at $8337 \mathrm{eV}$, the appearance of the $\mathrm{T}(\mathrm{d}, \mathrm{d}) 1 \mathrm{~s} \rightarrow 4 \mathrm{p}_{\mathrm{z}}$ peak at E2., and the shift of the primary white line feature to E4., and (20 ps) T(d,d). (B) The evolution of the XANES from -5 ps to 100 ps within the $1 \mathrm{~s} \rightarrow 4 \mathrm{p}_{\mathrm{z}}$ region. (C) Difference spectra relative to $\mathrm{S}_{0}$ spectrum for delays between -5 and $100 \mathrm{ps}$, showing the dynamics of the $\mathrm{S}_{0}$ bleach (E1), the rise of the $\mathrm{T}(\mathrm{d}, \mathrm{d}) 1 \mathrm{~s} \rightarrow 4 \mathrm{p}_{\mathrm{z}}$ peak (E2), the rise and fall of the transient at $8337 \mathrm{eV}$ within $2 \mathrm{ps}(\mathrm{E} 3$ ) and the rise of the white line feature (E4). Dotted lines correspond to energies at which delay scans were taken (Figure 3A). 

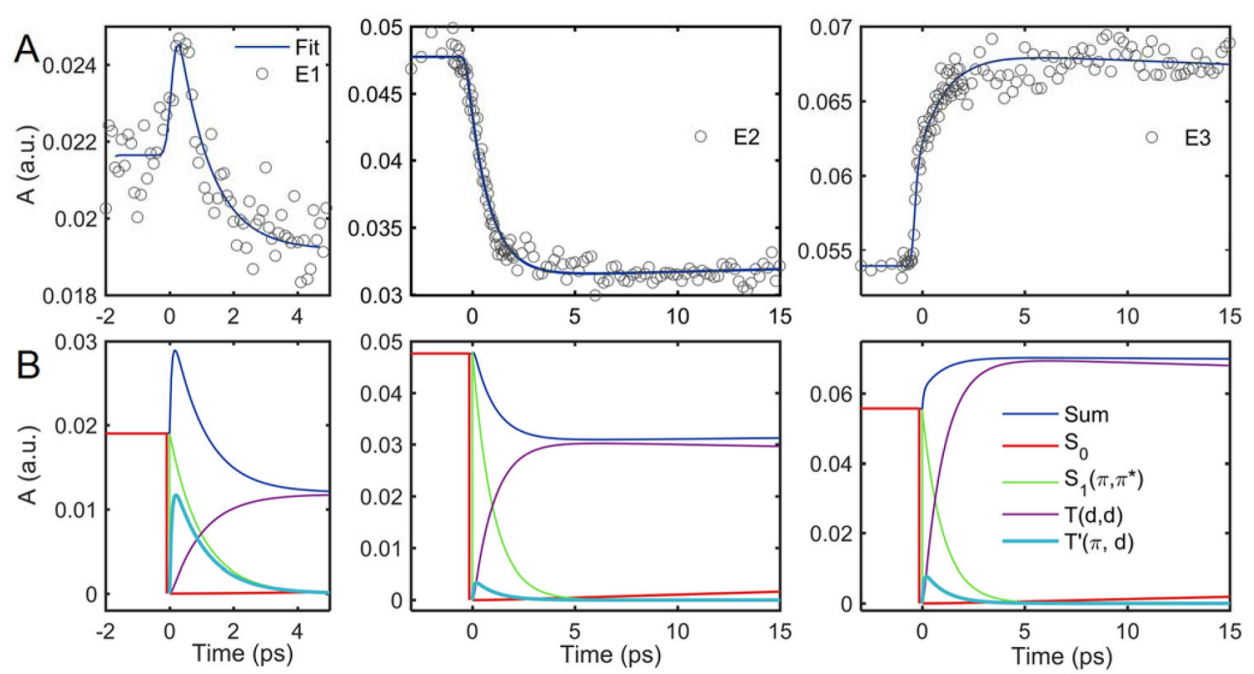

Figure 3.

(A) Single-energy delays scans at (left to right) $8337,8338.5$, and $8341 \mathrm{eV}$ with fits to kinetic model (1) (dark blue line). (B) Decomposed signal contributions from each electronic state accounted for in the fit of model (1) to the delay scans at (left to right) 8337, 8338.5, and $8341 \mathrm{eV}$ determined by numerical integration of the rate expression for each species, in this case for the assignment $\tau_{1}=1.0 \mathrm{ps}, \tau_{2}=0.08 \mathrm{ps}(<300 \mathrm{fs})$. The resulting total signal for each energy (dark blue) was fit to the delay traces. 

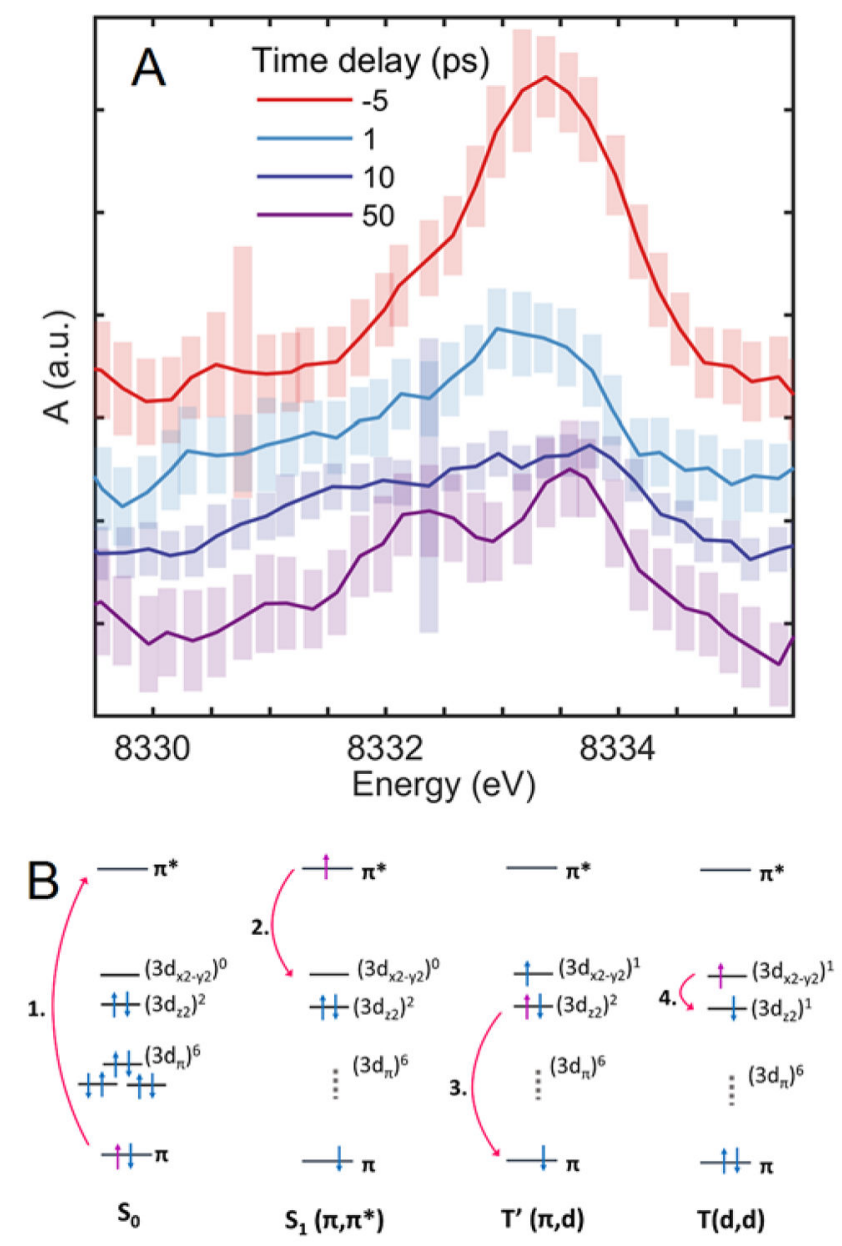

Figure 4.

(A) XANES scans in the $1 \mathrm{~s} \rightarrow 3 \mathrm{~d}$ region (Figure 2A, E0), $5 \mathrm{pt}$ smoothed and with the rising XANES edge background subtracted. Offset in A(a.u.) for clarity. (B) 3d-orbital occupations of electronic states in the NiTMP relaxation pathway resulting from: (1) excitation of the porphyrin macrocycle, (2) charge transfer from the macrocycle $\pi^{*}$ orbital to the Ni metal center, (3) reverse charge transfer from $\mathrm{Ni}$ to the macrocycle via relaxation of a $3 \mathrm{dz} 2$ electron into the $\pi$ hole, (4) relaxation of the $3 d_{x 2-y 2}$ electron into the $3 d_{z 2}$ to recover the ground state $\mathrm{d}$-orbital configuration. Note naming convention w.r.t. spin state. ${ }^{51}$ 

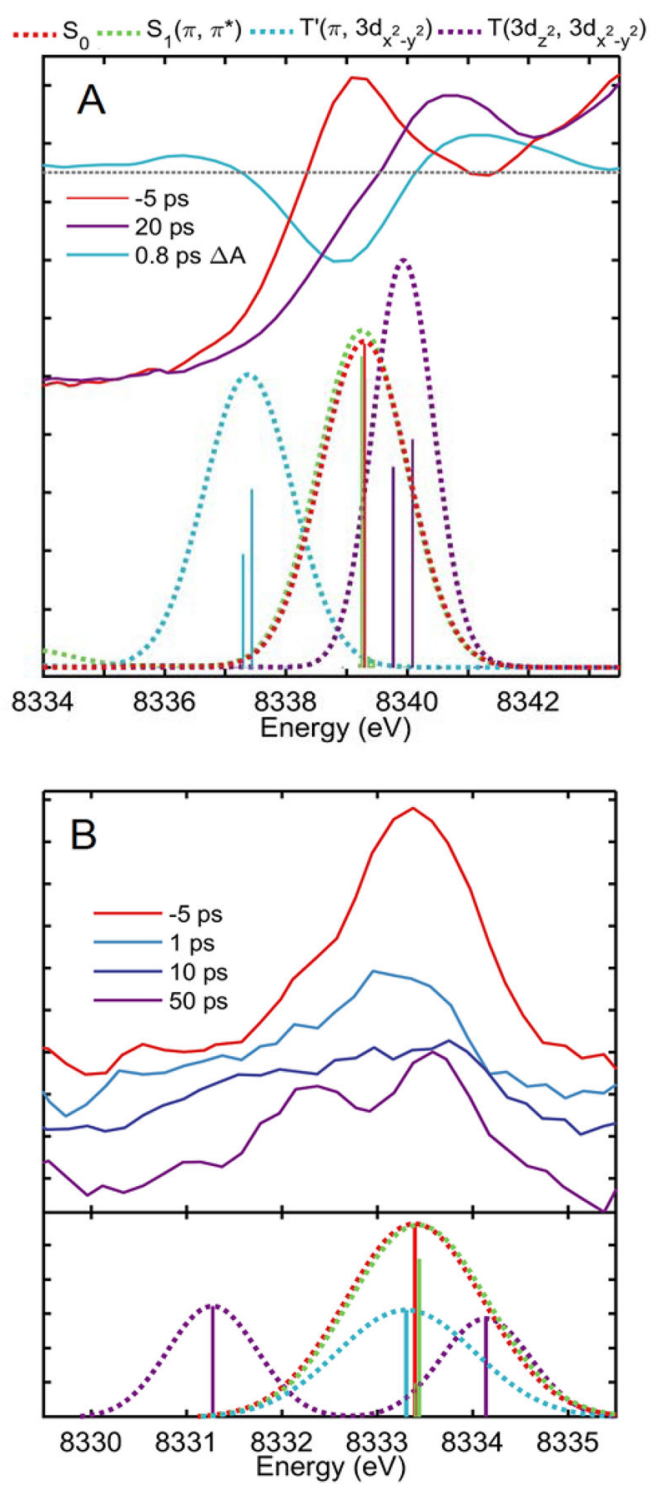

Figure 5.

Gaussian-broadened calculated XAS transitions of relevant excited electronic states compared to experimental spectra in (A) the rising edge regions where $1 \mathrm{~s} \rightarrow 4 \mathrm{p}_{\mathrm{z}}$ transitions dominate and $(\mathrm{B})$ the pre-edge region. 

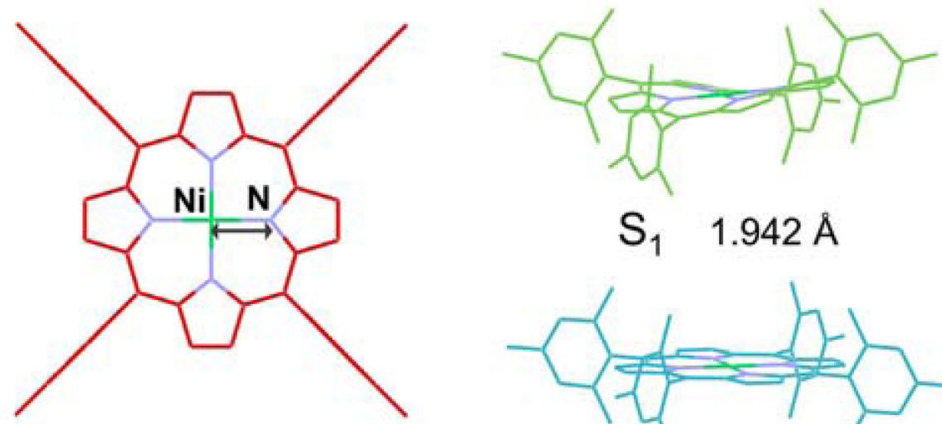

$\mathrm{S}_{1} 1.942 \AA$
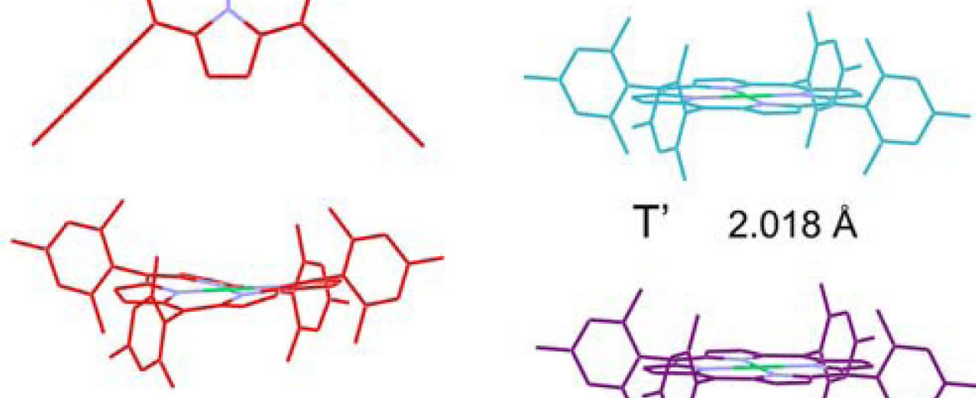

$\mathrm{S}_{0} \quad 1.942 \AA$

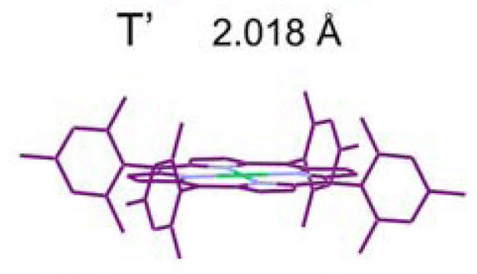

$\mathrm{T}(\mathrm{d}, \mathrm{d}) \quad 2.044 \AA$

Figure 6.

Relaxed geometries of each electronic state in the NiTMP decay pathway as calculated by TDDFT. Occupation of the $\mathrm{Ni} 3 \mathrm{~d}_{\mathrm{z} 2}$ orbital drives expansion of the $\mathrm{Ni} \mathrm{N}$ bond length and subsequent flattening of the macrocycle. 


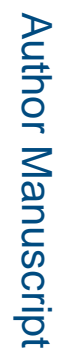

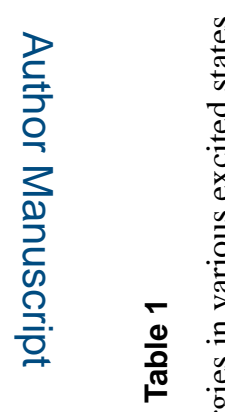

로을

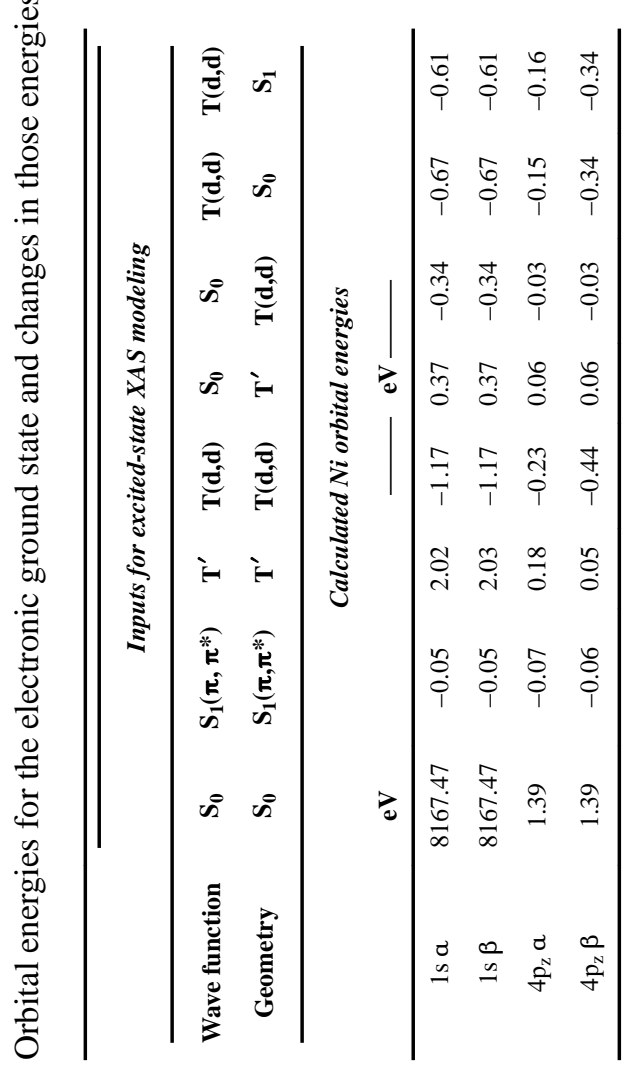

J Am Chem Soc. Author manuscript; available in PMC 2017 July 20. 